\title{
On understanding the impacts of shared public transportation on urban traffic and road safety using an agent-based simulation with heterogeneous fleets: a case study of Casablanca city
}

\author{
Jihane El Ouadi ${ }^{1,2,3,4}$ D $\cdot$ Hanae Errousso ${ }^{1,2,3,4} \cdot$ Nicolas Malhene $^{3,4}$. \\ Siham Benhadou ${ }^{1,2}$
}

Accepted: 15 November 2021 / Published online: 7 January 2022

(c) The Author(s), under exclusive licence to Springer Nature B.V. 2021

\begin{abstract}
Simulation and computer modeling have a key role in understanding transportation systems. Focusing on the main system, real-time retrieval of outputs based on mutual interactions of the whole autonomous entities makes the agent-based simulation very promising. This paper deals with an agent-based simulation to investigate and evaluate the potential impacts of implementing Shared Public Transports (SPT) in urban areas. Such a system is intended to integrate the two flows of passengers and containerized freights in Public Transportation (PT) patterns towards more sustainable, efficient, and socially suitable mobility. The proposed model is coupled with a stochastic process in order to provide a range of real-world data of Casablanca city (Morocco) based on institutional surveys. In this respect, two urban transportation systems of freight are tested: (1) the conventional transportation system, (2) the SPT system with heterogeneous fleets. In an effort to sustain efficient and safe movements, this paper examines SPT performances according to a set of key evaluation metrics. Results show that PT stopping remains the most relevant factor when evaluating metrics of the number of waiting containers and waiting time of demand by rates of $82.440 \%$ and $62.580 \%$, respectively. Such a waiting containers metric is significantly affected by the volume of demand to transport per time slot by a rate of $78.140 \%$. Under SPT, traffic congestion is the main factor to consider in managing PT with a rate of $65.690 \%$ in order to reduce potential accidents. However, demand volume could increase the on-street illegal parking metric by $90.070 \%$. More details are provided below.
\end{abstract}

Keywords City logistics · Public transportation - Shared vehicles · Passengers and goods · Agent-based simulation · Evaluation metrics

Jihane El Ouadi

jihane.elouadi@gmail.com; jihane.elouadi@ensem.ac.ma

Extended author information available on the last page of the article 


\section{Introduction}

The transportation demand, of both passengers and freight, is likely to increase over time as the city's population continues to grow (Ouadi et al. 2021c). As more and more urban companies and businesses continue to grow, transportation requesters were finding advantages to come together in demand zones (Ouadi et al. 2020a). Within these urban zones, service requesters carry out their freight shipments usually with owned or leased fleets. However, the major use of roads by private fleets increases traffic congestion and carbon emissions. Then, heavy-duty vehicles with low fill rates lead to long tours and further reduce the efficiency of drivers as many vehicles are needed to ship goods. These impacts are even more pronounced in cities experiencing plenty of local shops requiring deliveries with relatively restricted infrastructures (road, rail, and naval networks, highway tunnels, distribution centers, delivery areas, etc.).

The challenge of traffic congestion entails the efficient and safe mobility of passengers and goods in cities, which is considered a key impediment to sustainable mobility. According to the report of the INRIX association in the 2019 Global Traffic Scoreboard, the most congested cities suffer from high scores of traffic accidents and environmental problems. Actually, this remains clear due to the dramatic drop in traffic congestion and vehicle crashes in urban areas thanks to the COVID-19 lockdown (Aloi et al. 2020; Ouadi et al. 2021a). In this regard, interrelating urban congestion with such social factors is of prodigious interest in making various transportation policies for both people and freight. Such interrelation could also introduce a perennially issue to investigate new transport alternatives in order to prevent the potential generation of negative social effects as well as losses of economic efficiency. Ridership of existing PT, geography characteristics and illegal land use represent the ultimate factors that serve as the main root for rapidly worsening cities. In addition, they bring up a few fatal damages and thousands of slight and serious wounds every year around the world. In cities, urban traffic is responsible for the death of 1.2 million persons worldwide per year and injuries about four times as many (Wh 2020). In this respect, the World Health Organization (WHO) has stated that the direct cost of road traffic injuries worldwide is roughly $\$ 518$ billion per year, which offers insights into how serious are losses (Fancello et al. 2020).

Reducing carbon emissions from private vehicle traffic is considered a major issue in transport planning. one of the main impacts of PT in urban areas is air pollution. For example, in India, besides $\mathrm{CO} 2$, various pollutants such as carbon monoxide (CO), unburned hydrocarbons (HC), nitrogen oxides (NOx), sulfur dioxide ( $\mathrm{SO} 2)$, lead $(\mathrm{Pb})$, and suspended particulate matter (SPM) are also emitted from the passenger transport sector (Singh 2006). In 2013, the European transportation sector has emitted $24.4 \%$ of the region's total GHGs, $94.6 \%$ of which has been come from road transportation (Osorio-Tejada et al. 2017). Including freight and passenger transportation, this sector accounts for a large portion of annual energy use and greenhouse gas emissions (GHG) in the United States; approximately $30 \%$ of energy and 33\% of CO2 emissions (Nealer et al. 2012). However, freight transportation accounts for only a portion of total transportation energy use and emissions, about $30 \%$. Similarly, freight transport in the United Kingdom is estimated to generate 33.7 million tons of $\mathrm{CO} 2$, thus, about $21 \%$ of transport sector emissions and $6 \%$ of total emissions from all sectors. In this respect, road transport is responsible for $92 \%$ of these transport-related $\mathrm{CO} 2$ emissions.

However, the measures generally proposed in urban transport plans seem to be aimed mainly at different objectives, including the reduction of traffic congestion, improvement 
of public or alternative transport modes, with a subsidiary role for $\mathrm{CO} 2$ emissions. Other forms of sustainable energy action plans have been proposed, but these also do not fully take into account the complexity of the integrated transport approach. In this respect, a cost-benefit analysis of bicycle and pedestrian networks in three Norwegian cities has been performed (Nocera and Cavallaro 2014). The cost-benefit analyses take into account the benefits of reduced safety and the health benefits of improved fitness from the use of nonmotorized transport. In addition to the reduction in health costs, the analyses also take into account the fact that switching from car to bicycle or walking leads to a reduction in external costs (e.g., air pollution and noise) associated with motorized traffic and a reduction in parking costs (Sælensminde 2004). The marginal external costs of congestion, air pollution, road accidents, and noise have been estimated and proposed in the literature (Sen et al. 2010). As the results suggest, motor vehicles operating (e.g., in Delhi) almost certainly impose very large social costs, most of which are not borne by the users. Thus, there is a strong argument for optimal road pricing based on marginal social costs.

To reduce congestion and the issues it causes, it is required to improve the PT's attractiveness and market share for witnessed substantial growth in service efficiency. Shared transportation systems otherwise -known as integrative mobility- are among the proposed alternatives. They have been conducted using various systems and resources. From a flow (commuter and freight) perspective, it could be conducted through several types. For example, combined transportation has enabled travelers and freight, with identical itineraries, to take the same car for sharing transportation costs and satisfy demand using fewer vehicles (Wang et al. 2020). In this type of shared transportation, PT systems, (Trentini et al. n.d.) taxis ( $\mathrm{Li}$ et al. 2014), and private vehicles (Beirigo et al. 2018) are involved. The share-aride systems account for another shared logistics that integrates parcel and passenger flows in the same taxi (Wang et al. 2020). Furthermore, crowdsourcing-based transportation has been a tool in shared transportation applications that share the scheduled trips to carry freight. This alternative could consider passengers, which adds a set of modeling parameters including synchronization, capacities, facilities, etc. (Chandra et al. 2019). During idle time, freight is loaded in residual capacity in order to achieve its destination through the passenger network avoiding the loss of service quality.

Actually, city dwellers could get a set of common vehicles using PT such as bus, tram, and train that operate at regular time on fixed paths with affordable costs. Over time, researches have based on planners' previous knowledge and local communities' requirements to investigate PT travel behavior (Berggren et al. 2019; Ngoc et al. 2017), operations of demand-responsive (Gkiotsalitis and Stathopoulos 2016; Huang et al. 2020), and schedauling the fleet size that connects metropolitan and residential areas (Manser et al. 2020; Liu et al. 2019). PT has played, subsequently, a major role in relieving traffic congestion. Nonetheless, there are few studies that focus on PT applications, emergent technologies, and potential future policy scenarios (Nguyen-Phuoc et al. 2020). The growing logistics demand, especially in urban areas, as well as emerging technologies create both opportunities and challenges for efficient shared schemes that improve transportation service and sustainability. Integrative transportation through shared PT fleets to free the city from the extra traffic is one path to achieve city logistics goals. Within a combined delivery system, residual capacity could be deployed for supply operations during peak-off time slots. As such, using residual capacity on journeys for freight delivery requires specifying whether to transport only passengers or increasing operational efficiency to integrate freight. However, sharing car capacity for a trip or a trip part must respect passenger preferences and provides lower costs with no added travel time. This alternative is likely to achieve cleaner air and reduce gas emissions as well as less traffic in urban areas. 
On the other hand, for commuter and freight transportation systems, the operational strategy is considered the most common feature to reduce the overall cost and pollution emissions for achieving a rational use of available resources. Basically, operational scheduling refers to managing locally on a short-term horizon routing flow regardless of the type of corridor. For seeking to keep minimized the empty places in shared vehicles, management decisions to be made comprise when to relocate what amount of freight to ship between nodes. However, there are further operational challenges to successfully shared transit within the operational conditions. That is, scheduling freight movements using already available passenger cars of PT presents significant challenges to provide feasible movements in an operational timetable. In this paper, we propose dynamic operational scheduling for shared PT vehicle routing based on consolidation hubs. As such, freight routing using the proposed system needs to use the actual traffic conditions.

The rest of this paper is structured as follows. Section 2 highlights the relevant researches focusing on the operational management of transportation systems. Section 3 describes the proposed SPT system and spots key issues towards preliminary feasibility assessment for implementing such systems. Next, more details on the adopted methodology and the simulated urban environment are provided in Sect. 4. Experiments and numerical results are intended to evaluate, in Sect. 5, the performance of the SPT by comparing it with the conventional system for a set of realistic parameters on a case study of Casablanca city. In Sect. 6, a critical discussion of the SPT impacts and challenges in a real-life framework is provided. Finally, Sect. 7 summarizes our findings and perspectives.

\section{Operational management of transportation systems}

\subsection{Existing approaches}

Operational management of transportation is typically about optimizing the flow routing of commuters and goods within a set of constraints so as to reduce vehicle miles, travel time, and the number of required vehicles (Schenekemberg et al. 2020). In addition, the goal is to determine the optimal routes for fleets considering a level of service performance ( $\mathrm{Lu}$ et al. 2020). This implies ensuring a capacity to carry in good conditions given a type of traffic, in terms of availability, throughput, transmission delays while considering the routing limitations (Ouadi et al. 2020b). Thus, operational management helps fleet managers plan routes that can maximize fleet efficiency and minimize last-mile delivery costs. In the case of shared transport, this management is based on the responsibility of the transport service between users through optimal scheduling of shared resources, trips, itineraries, and shuttles (Ouadi et al. 2021a). To investigate such operational management, a wide variety of approaches has been applied as methodologies to address mobility actions planned in the short term (Fig. 1).

\subsubsection{Mathematical approach}

The Vehicle Routing Problem (VRP) has been a popular topic in the operational management of transportation systems including shared ones over the past decades (Gansterer and Hartl 2020). It involves determining a set of vehicle routes so that each customer is visited exactly one time while minimizing the overall costs. A set of VRP 


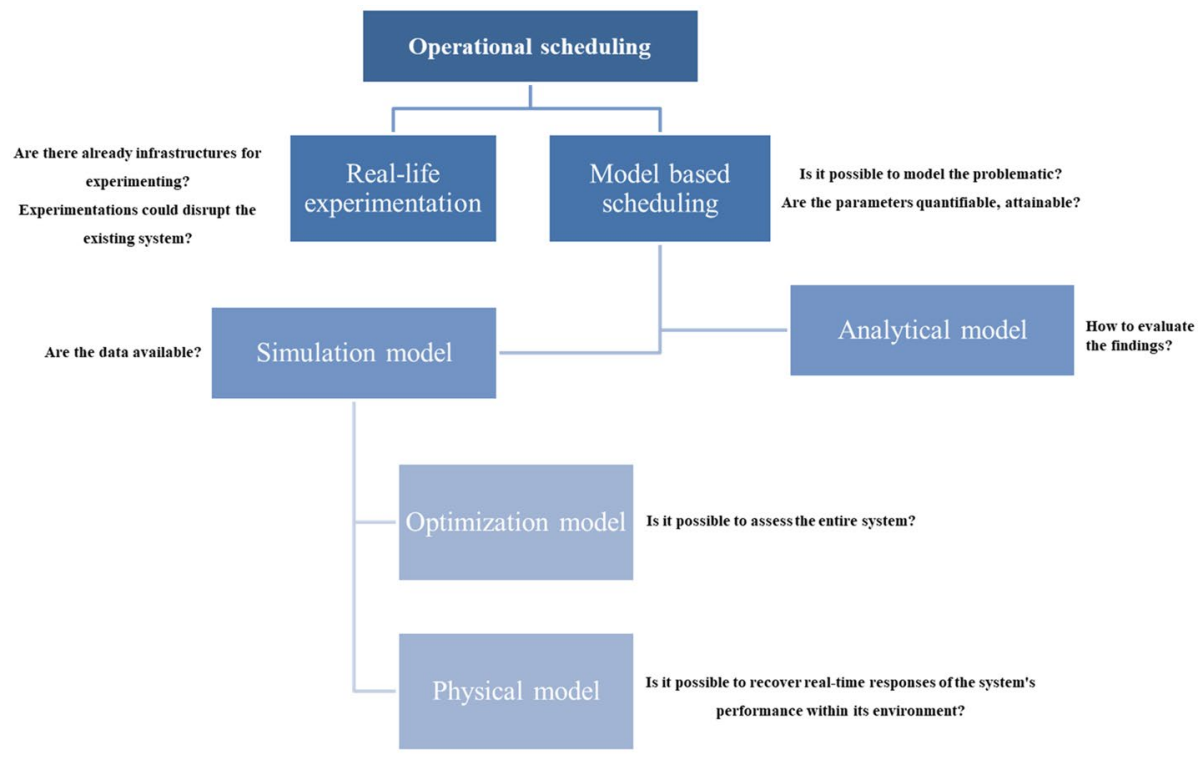

Fig. 1 Operational scheduling approaches

extensions against VRP variants (Table 1) such as capacity, time window, service type, fleet type, etc. have been developed. Thus, VRPs with several variants have been largely addressed in the literature.

With the evolution of demand for transport, real-time data is still needed when deliveries of many requests are in progress. In this respect, dynamic VRPs (DVRPs) become increasingly relevant to support delivery schedules in a way that minimizes transportation costs, pollution, and delay. A shared transport could use DVRPs to prompt freight delivery for real-time route changes based on road conditions and scheduled time slots of users (Ulmer et al. 2020). In urban freight transportation, a VRP with synchronization constraints requires customer deliveries by one or more logistics service providers. To deliver goods with an efficient idle time, the authors of the paper (Sarasola and Doerner 2020) have proposed a strategy that relies on self-imposed time windows. The results have shown that the proposed route problem with time windows allows predicting the departure time and path of each vehicle, which reduces congestion and total costs.

In addition, the problem of reducing carbon emissions and fuel consumption during shipping trips is identified in the literature as green VRPs. In this respect, paper (Liu et al. 2020) has investigated the problem of routing electric vehicles of urban mobility of freight within a sharing economy context. It has taken into account carbon taxes and time-of-use as time-varying electricity prices. Involving the Ant Colony algorithm, it has proposed optimization of routing electric vehicles dedicated to freight transport. Also, in paper (Wang et al. 2019), the problem of environmentally friendly routing of multi-depot vehicles has been addressed within a resource sharing strategy. This VRP extension has incorporated the time-dependency of speed as well as piecewise penalty costs for deadline delay of deliveries. Based on a set of heuristics, the proposed model has aimed to minimize total carbon emissions and travel costs while imposing penalties to reduce wait times and improve customer satisfaction. 


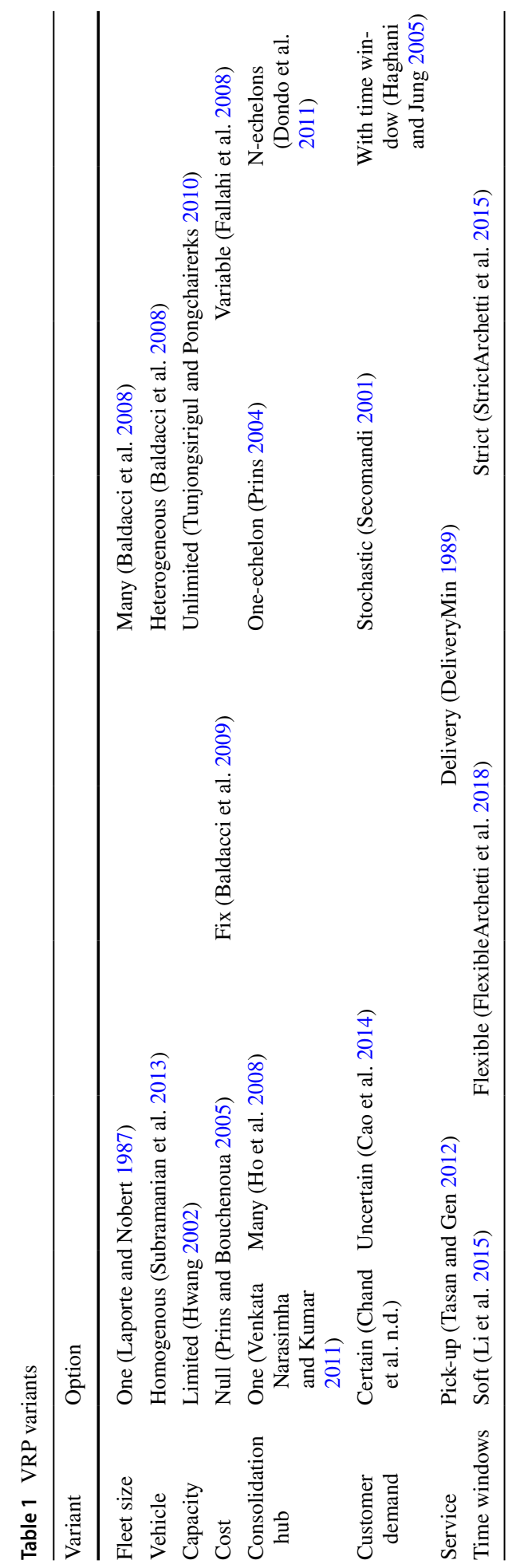




\subsubsection{Simulation approach}

In addition, simulations have been less used techniques in modeling transportation systems, especially shared systems. A simulation model of bus service has been developed in the paper (Moosavi et al. 2020) to fill the gap of PT reliability. This research has intended to cover both passengers' and operators' perceptions of reliability: waiting time, on-board crowding level from the passengers' perspective, and so on. The model results have shown that control strategies such as progression-based distribution could significantly improve progression consistency and average waiting time. Paper (Andersson et al. 1979) has suggested an interactive simulation model to assess the urban bus route during the peak of traffic congestion. This simulation model has provided a tool for route control operators and acted as a guide to help users to better assess the impact of individual behavior in the system. In addition, the paper (Sayyadi and Awasthi 2018) has addressed a simulationbased optimization approach for identifying key determinants of sustainable transportation planning. In this paper, it has been combined sequential steps based on system dynamics of sustainable transportation planning and key factors optimization.

\subsubsection{Analytical approach}

However, in paper (Dlugosch et al. 2020), authors have revealed the benefits of both analytical and simulated decision supports in understanding urban transportation. Based on a case study, they have shown that autonomous electric vehicles of shared transport could reduce resource investments while keeping a given service level. The paper (BuenoCadena et al. 2020) has established an analytical model to control disruptions on a subway line by introducing a congestion-sensitive formulation of the user's travel time cost. It has controlled a set of strategies including a combination of speed control and holding strategies based on the result of analytical models. In this respect, an analytical model has been proposed for the many-to-one process of demand-responsive transit service (Huang et al. 2019). The agency and user costs have been approximated by closed-form expressions. In this sense, the Vickrey Queueing theory and the Nearest Neighbor Routing approach have been implemented so that the vehicle still picks up the closest passenger waiting in the system. The paper (Papanikolaou and Basbas 2020) has explored demand-responsive transport services as a case study of efficient mobility service delivery for low-demand intercity areas. Hence, an analytical model has been carried out and applied in a real-world case identifying critical demand thresholds for alternative modes. The analytical modeling has highlighted the trade-offs between costs and the level of service that a transport operator or mobility provider must take into account.

\subsubsection{Agent based approach}

Since freight mobility is the interaction of many decisions making, the modeling approach should be able to represent many urban actors behaving autonomously. Modeling the physical components of urban freight transport must be developed as a physical simulation able to reproduce the intrinsically dynamic operation. Agent-based modeling is an alternative that analyzes stakeholder decisions and detailed behavior by modeling each individual entity as an agent. Agent-based modeling aim broadly to integrate multiple perspectives that processes information exchange with other agents to make dependent decisions. 
In this respect, the impact of each decision-making made by such heterogeneous entities is addressed to capture autonomous behaviors that are integrated into the whole dynamic environment.

Agent-based modeling is a powerful technique that has seen a number of applications in the literature for simulating transportation systems. Authors in paper (Inturri et al. 2019) have been presented an ad-hoc agent-based model using geographic data to explore different system configurations of demand-responsive shared transport service. The simulation results have analyzed, then, the impact of fleet composition and route selection strategy on system performance. Thus, the total unit cost indicator of vehicles has been minimized taking into account both passenger travel time and vehicle operating cost. Authors in Martinez et al. (2015) have proposed an organizational design and pricing scheme that aims to use the capacity in traditional taxi services in a sharing model with lower costs. The paper has employed an agent-based simulation model in which a common set of rules for matching space and time between demands and candidate shared taxis is recognized. It has considered that the client is willing to accept a maximum deviation from his direct route and establishes an objective function for selecting the best candidate taxi. The achieved results have shown that the proposed system can provide considerable savings to passengers in terms of fares and travel time while not exposing revenues as much.

However, paper (Anand et al. 2019) has focused on experimenting with the delivery ceiling and cost. It has shown the related policy with a conventional implementation of a city logistics agent-based model for the inner city of Rotterdam. This policy has been based on the carbon credit point mechanism combined with a subsidy for urban consolidation alternative to support the implementation of the United Nations convention, Kyoto Protocol, on climate change. In a large sense, this implies that by limiting the number of direct deliveries per supplier, carbon emissions can be controlled. Paper (Bok and Tavasszy 2018) has discussed a conceptual prototype of the agent-based modeling framework of urban freight transport. The prototype holds the agents (producing and consuming firms), synthetic shipments, and a baseline tour-formation procedure. This model's advantage is to generate extensive freight transport observations (from both own account carriers as 3PL's). Using Global Positioning System (GPS) tracks of commercial vehicles and network theory concepts, this work (Viljoen and Joubert 2019) has examined the characteristics of micro-communities in the supply chain in three urban areas of South Africa. The proposed model could make it possible to deduce urban freight transport patterns from supply chain interaction.

\subsection{Gap in the literature}

In the field of shared transport, social impacts and their sub-issues in different zones of the city have generally been regarded as subsidiary or even tertiary concerns compared to economic and environmental impacts. However, sharing resources during certain time slots of the day could have dramatic consequences on city traffic. In addition, the lack of realistic frameworks prevents urban shareholders from understanding the full interaction with the urban system before proceeding with implementation and actual experiments. Although promising, physical simulation trends remain underutilized compared to analytical and exact approaches in evaluating the behavior of mixed urban transportation systems. This gap is probably related to the lack of data on the urban transport situation as well as saved information describing the response of the areas hosting the policy experiments. Although such data already exist, academics and researchers have great difficulty in obtaining them 
because they are not always distributed in open source. In addition, data collection can be done through surveys and questionnaires, but these can be very expensive and timeconsuming to conduct.

\subsection{Paper contribution}

Considering the gaps identified in the literature as well as the current trend towards simulation and computer modeling, this article proposes:

- Consistent review: that summarizes knowledge base of operational management approaches used in the literature.

- Quantitative assessment: of the suggested SPT system with heterogeneous fleets (Sect. 3) comparing with the conventional freight transport.

- Urban traffic and road safety metrics: although urban traffic and road safety are key metrics, they are not widely addressed, particularly in the area of shared transport. They are analyzed in this paper in order to reduce the potential risks of sharing PT to enable sustainable patterns of urban mobility.

- Systemic behavior analysis: that evaluates in real-time and within a systemic framework the transport alternative as a part of an urban environment rather than an isolated system to properly investigate its sustainability and reliability at specific zones and time slots.

- Exploiting governmental surveys: in the proposed agent-based simulation to better estimate the effects of SPT including stochastic processes based on knowledge data retrieved from government institutional reports.

- Case study: of Casablanca city for urban players interested in the institutional-based processes of new transport policies assessment. Such a case study might contribute useful insights to develop decision-making and relevant theory both within or outside Morocco for two key reasons. The first reason is the special place that Casablanca holds in Morocco in particular and in Africa in general. It represents the main driving force behind Morocco's economic development and remains a key economic trade node for the Africa-Europe region. The second is the absence of systematic and quantitative researches to assess the social aspect of accidents and the illegal land use in sharing logistics facilities.

\section{Implementing a consolidation-based system for urban SPT}

\subsection{System description}

We investigate, in this paper, the benefits of an SPT alternative (Fig. 2) that aims to provide rational use of the residual capacity during idle times. In this respect, priority is always given to the passenger. The SPT vehicles (Fig. 3) would not add to congestion for the extra job since they are already in operation. The aim is to evolve towards a resilient city by breaking new patterns in terms of mobility service provision supported by the least infrastructure investments. Such exposition of the existing PT system ensures that passengers and/or goods are routing within the same transport vehicle as per an already set timetable. As such, we aim to connect urban areas where customers requiring frequent deliveries are located relying on consolidation hubs. With demand volatility that 


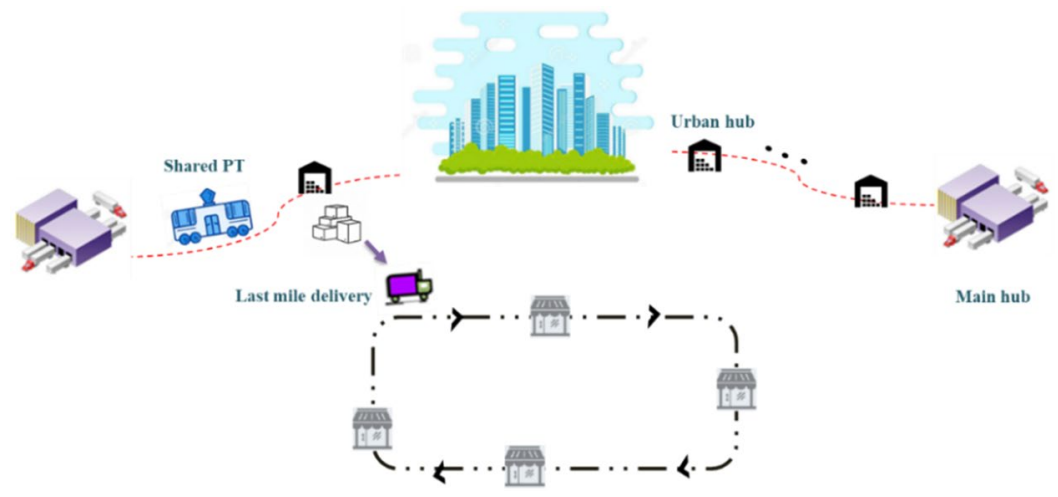

Fig. 2 Illustration of an SPT system
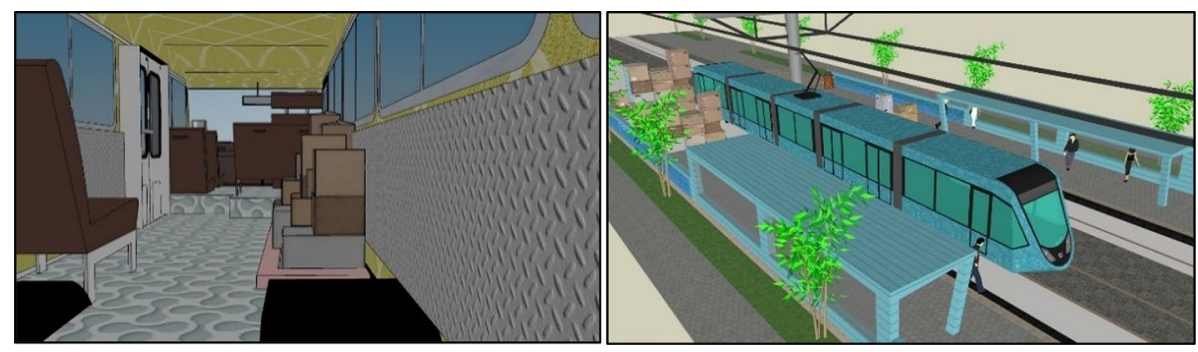

Fig. 3 Examples of SPT vehicles in urban areas

sometimes can exceed the residual capacity of the vehicle, goods are stored in hubs before being reloaded into another vehicle with sufficient residual capacity.

Establishing a freight consolidation network would provide safe traffic without deteriorating passenger service, delays, and frequencies. In order to eliminate needless movement and overexploitation of urban land for these logistics infrastructures, relevant experiments could be carried out on the basis of a two-echelon consolidation of goods. The first echelon is given by logistics hubs for mass transit located upstream of the transport network. Its purpose is to accommodate the flows that must enter the city and organize goods to be transported by PT. The second echelon consists of urban platforms that are arranged along with the PT network. A set of light vehicles assigned to each hub ensures good delivery to the final recipients by means of short trips. Typically, system components are given by the following:

- The main network, i. e., a PT system (tram, bus, etc.).

- The two-echelon of consolidation hubs.

- Light vehicles assigned to urban hubs to allow delivery to the final recipients through short delivery trips.

The multi-variant nature that each component could generate accentuates the level of complexity. That is, our goal at this stage is to provide a decision-support tool aiming at 
optimized operational scenarios. Different alternatives in various scenarios could vary performances, but they all fit broadly within the most efficient framework.

\subsection{Feasibility assessment}

Implementing SPT continues to face a challenging environment due to rapid urban growth, environmental pressures, and increased costs. In this sense, the feasibility analysis phase is required to assess the system constraints, relative targets, expected changes, restrictions of resources, etc. to provide guidelines to any potential implementation issue. This prior assessment helps to meet challenges and anticipate achievements. Based on the above components, there are a set of key conditions -mentioned in the following-that are to be explored to successfully meet the needed requirements.

Urban stakeholders. Shared mobility services require large-scale partnerships between the overall players, which is quite challenging due to the divergence of their aims and goals (Gonzalez-Feliu et al. 2018). It cannot be achieved without the contribution of urban stakeholders to express their interests, investigate collaboration and adopt common pronouncements (Kim et al. 2015). Such actors, i.e., city actors, transportation actors and community actors, are contributing to combining funds and building a synergistic approach for assessing the strengths and weaknesses of last-mile transportation alternatives as well as reducing the generated costs and ecological impacts. Funding sources. Funding sources. The SPT could be funded by the public or private sector with capital coming from general funds or taxation (capital recovery is anticipated). Hence, uncertainty in earnings would probably lead to misalignments between the relevant transportation alternatives that are proposed by the partners and the provided funding support. This underlines the major challenge of assessing the impacts of logistics schemes related to capital investment projects on the urban supply chain (Nordtømme et al. 2015). These factors make the funding initiatives rather insufficient to implement, sustain and enhance the system's performance. Transport infrastructures. One of the main concerns is the potential of existing transport infrastructures. The respective role of transport infrastructures is not limited to flow traffic. They set the level of accessibility to the main zones and locations in order to serve a multiplicity of users. Urban areas are often restricted within a limited space, where urban areas are either contiguous or linked to connect centers of economic and social activities. In shared mobility, infrastructures are used for transporting commuters and cargo together by private or public vehicles. Under a systemic logic, this could better manage existing infrastructures as passenger and good flows influence each other since they share at least one common resource, i.e., road network (Mommens et al. 2018). Loading and unloading areas, parking and logistics facilities for storage and distribution of merchandise require further space and features to handle shared shipments. However, some cities may not provide sufficient infrastructure to support new shared transportation initiatives. City characteristics. City characteristics are important to share PT systems and they remain to be seen whether the intended novel system would be maintained in long term. Some of the significant characteristics of urban areas are size, level of development and, type (number) of activities that are performed. In other words, the proposed system would not work properly as well as attract the same potential users in each city. The achieved benefits may not be the same and make, in fact, the initiative aborted or failed (Grange et al. 2012). Interoperability. A city is a system consisting of a set of sub-systems with various goals. Behind every sub-system, there are actors, targets, and relative patterns, all of which are positively correlated and interact as a whole. This makes urban dynamics more complex and harder to interoperate 
at intersection layers of the system (Deniaud et al. 2012). The above constraints entail mixing the routing of the two flows, freight, and passengers, based upon selection features of roads toward the destination (being updated at each intersection) (Gnimpieba et al. 2015). The suitable approaches of interoperability include transport timetables optimization and processing delay optimization for offering appropriate routing protocols capable of distinguishing between different types of users. Regulatory policy. SPT to be implemented, whether roads, railways, buses and so on require legal frameworks. The legal framework is valued as a support tool for planning shared use and evaluating impacts and opportunities that are relevant to the concerned players. When looking at regulation supports, making decisions is not the core aim but they improve the evaluation against the other alternatives in terms of social, environmental, and economic scopes (Dablanc 2007). They contain further spatial and temporal restrictions adapted to the characteristics of the city in accordance with the national legislation framework (e.g., vehicles with a maximum permissible laden weight greater than 3.5 tones are subject to spatial and temporal restrictions). The expected benefits for the shared transportation organization of such measures are based on restricting infringing vehicles, easing control, streamlining flows, optimizing loads, and scheduling the city's delivery operations at peak times (Dablanc 2008).

\section{Adopted methodology}

The operational scheduling problem discussed in this paper addresses an integrative timetable synchronization with the already planned PT trips and the last-mile traffic system. In doing so, we assume simulation of an SPT model based on interactive agents (Fig. 4). The aim is to entail scheduling within local zones under short-term management of flows for providing dynamic behavior of traffic. In the last mile sub-areas, the model deals with sharing PT trips with freight flow in order to achieve customers and transshipment hubs rather than using the conventional system. Each proposal is obtained from a set of stochasticdiscrete events that are able to replicate the natural dynamics in a city wielding influence over the soundness of scheduling plans.

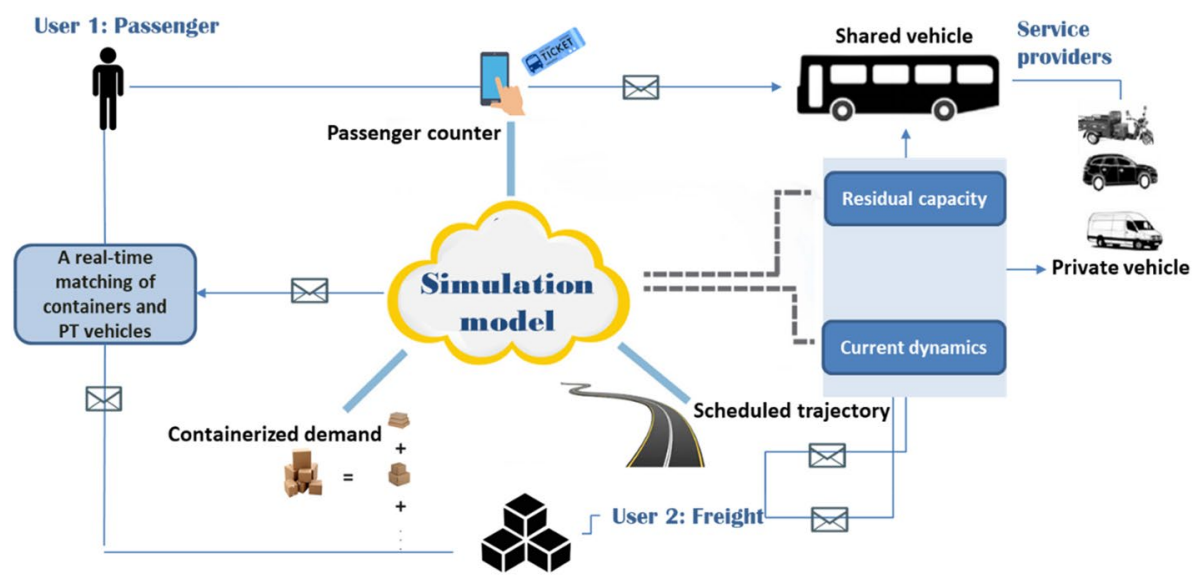

Fig. 4 Overview of key elements of the proposed SPT system 


\subsection{Model concepts}

The implementation of SPT highlights a whole range of issues arising out of the integration of passengers and goods on shared trips, including transshipment, containerization and itinerary planning.

\subsubsection{Transshipment process}

To be transported in an integrative way, freight could shift from the shared car to other modes, which offer much flexibility in transport scheduling. Belonging to the strategic layer, transshipment platforms allow transfers from one mode to another with easy loading and unloading onto and off vehicles. These facilities organize the splitting or composition of orders as far as a consolidation system is concerned (Ouadi et al. 2021b). Efficient coordination of freight with regularly shared PTs is strongly linked to the aggregation of discreetly arriving flows across the residual capacity, which varies with time slots and the level of urban congestion. Beyond the volatility of residual capacity that compels shippers to combine fragmented deliveries to achieve a higher total volume, transshipment remains important to bring demand closer to the customer.

Assumption 1 The SPT can directly supply the final customer; in this case, we have two types of recipients: transshipment hubs and final customers.

\subsubsection{Containerization process}

To streamline the systematic shift of freight for reaching hub and customer sites based on PT vehicles, standard packaging is required for handling convenience and transport quality (Mizutani and Fukuda 2020). Containerization increases the likelihood of modal share over road and rail networks, as it allows transport to achieve the critical mass essential for sustainable performance (Woodburn 2017). As shown in the paper (Hai et al. 2020), traffic volume on public roads decreases notably with a containerization process. It enables smoother and faster freight processing. For multimodal transport, the optimized stock-pooling in integrated strategies have been investigated with container forwarding. As a result, containerized goods are deemed relevant for the system efficiency of intermodal transportation using stochastic dynamics (Zhang et al. 2019). In addition, the impact of containerization is obvious in fuel consumption regarding size and mass. Thus, instead of assuming total energy consumption to shift freight, the impacts of relieving have to be assessed according to standard cargo containers (Buchanan et al. 2018). In this respect, the Physical Internet (PI) approach has furthermore confirmed that it is necessary to involve different types of modular PI-containers in order to reduce large-scale issues. Integrating PI-containers serve not only to attain ecological challenges of city logistics but also to increase the efficiency of handling, storage and transport of goods (Sallez et al. 2016).

Assumption 2 Demand in the SPT system from (to) every source (destination) is assumed on container format. 


\subsubsection{Routing process}

Integrated transport patterns reflect the link and complementarity between passenger and urban freight schemes. As the two schemes cover different segments of the transport sector, they are considered complementary because mobility systems are designed to carry only passengers or freight that share at least routing paths. Integrated schemes concern a variety of large and light modes used in combination to provide door-to-door services. In other words, buses/trucks could compete with a private car to minimize the total travel miles. They ensure the distribution of goods through logistics platforms that are supported by capacitive corridors. Afterward, the cargo is unloaded/loaded to reach a second consolidation platform. A light distribution system is associated with each platform that carries out deliveries to the final recipients by means of light trips within urban zones.

Assumption 3 Existing PT scheduling will not be affected. The aim is to assign the already scheduled journeys to commuters and containers waiting for shipment.

\subsection{Communication and dynamics protocol}

\subsubsection{Preliminaries}

Within the operational scheduling of such SPT system, a series of features require managing in order to monitor flow dispatching between facilities and logistics nodes that are set up at the strategic scheduling (Diabat et al. 2013). Thus, the simulation model revolves around a set of agent populations. For each population, let us consider primarily a number of sets of elementary agents considering an indexation by $i=\{1,2,3, \ldots\}$, where $i \in \mathbb{N}^{*}$ :

- Z: the set of urban zones;

- $\mathrm{S}$ : the set of shops;

- H: the set of hubs;

- V: The set of private vehicles;

- L: The set of PT vehicles;

- D: The set of drivers of PT vehicles

- G: The set of journeys;

- P: The set of passengers;

- C: the set of containers;

- U: the set of users of PT;

- Pt: The set of paths.

- SP: Stop stations.

The decision to share PT vehicle depends not only on the demand volume and the residual capacity, but also on the physical distance to the delivery location, i.e., hubs and shops. In this respect, a set of shops $s_{i} \in S$ and hubs $h_{i} \in H$ is dynamically located within each urban zone $z_{i} \in Z$. For accomplishing freight forwarding to the final customer a set of private vehicles $v_{i} \in V$ carrying on the same transportation network might consider the self-fulfillment or the outsourcing carriers. In this respect, a hub $h_{i} \in H$ is further distinguished by a set of demands that could be loaded/unloaded during the stopping time of a PT vehicle. A PT vehicle $l_{i} \in L$ is scheduled per time slots $\tau_{i} \in \tau$ to 
carry passengers $p_{i} \in P$ and /or freight containers $c_{i} \in C$. Depending on a time slots $\tau_{i}$, two users of this system are considered namely containers and passengers: $U_{\tau}=C_{\tau} \cup P_{\tau}$

A container $c_{i} \in C$ is characterized by a standard capacity $C_{c}$ an origin $o_{c_{i}}$, a destination $d_{c_{i}}$, an earliest departure time $d t_{c_{i}}$ and a latest arrival time $a t_{c_{i}}^{\prime}$. Each container is distinguished by a maximal time of delivery $M T D_{c_{i}}$ allowed by the final recipient as well as a suggested time of delivery $t_{D}$ issued by the SPT. Likewise, a PT vehicle $l_{i} \in L$ is characterized by an origin $o_{l_{i}}$, a destination $d_{l_{i}}$, an earliest departure time $d t_{l_{i}}$ and a latest arrival time $a t_{l_{i}}^{\prime}$. The integrated schedule embeds the time a container spends on waiting for a PT vehicle taking into account the interests in attaining reduced involved resources. Given that combined use is reported, the long waiting time compels demand to shift to a private vehicle $v_{i} \in V$, which have a negative impact on the SPT performances.

The operational scheduling problem here could be useful to make undisturbed planning with a reactive assignment of containers to a set of journeys $g_{i} \in G$ of a PT vehicle carried out through a set of paths $P t$. Each path $p t_{i} \in P t$ is comprised of a set of consecutive stop points SP where firstly passengers are pick-up/dropped and then goods. Besides time and distance constraints, a driver $d_{i} \in D$ accept to share a vehicle $l_{i} \in L$ if journeys are matchable regarding the residual capacity through two successive stations $R_{c}^{h_{i-1, i}}$. We assume that the total capacity of a PT vehicle $C t_{l_{i}}$ is not fully considered in the sharing schedule in order to ensure passenger comfort. A ratio $\omega$ of this capacity is retained to assign demands to the usable capacity including minimal shared capacity $M S C_{l i}$ of a vehicle $l_{i}$ (Eq. 1).

$$
M S C_{l i}=\omega * C t_{l_{i}}
$$

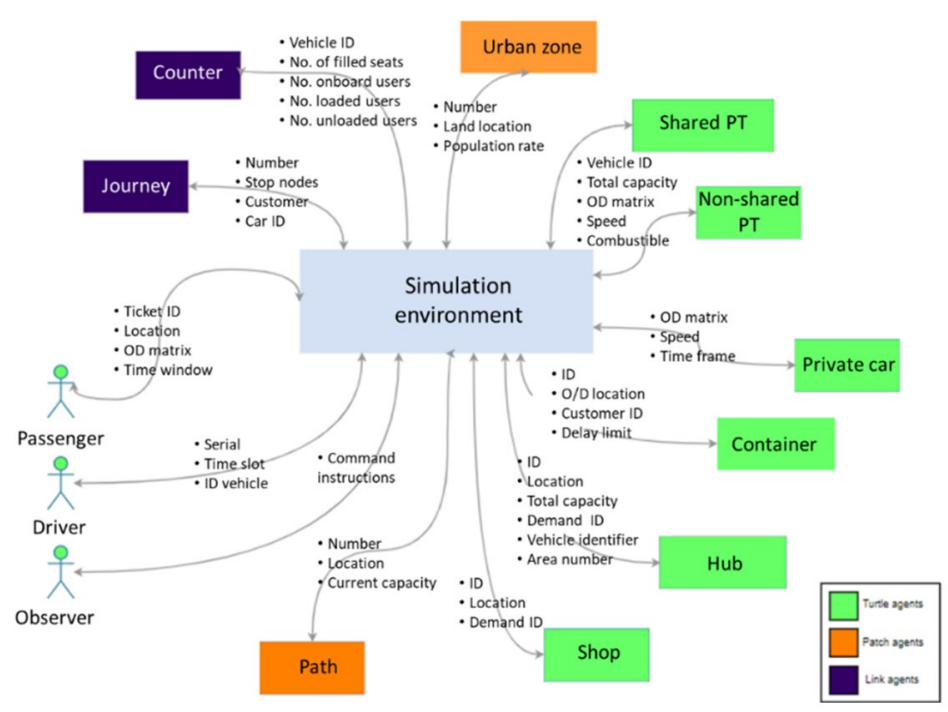

Fig. 5 Types and attributes of interactive agents in the simulation environment 


\subsubsection{Agent behavior}

With deterministic approaches, it is almost powerless to take the whole components of the urban transportation system, i.e., traffic conditions, congestion times, the uncertainty of user arrival, traffic signals, pedestrian areas, road rules and so on. Per contra, stochastics interactions can deal with SPT system as a subsystem of the city system with pervious components.

The simulation model encompasses a set of agents $A=\left\{a_{1}, a_{2}, a_{3}, \ldots, a_{n}\right\}$ that consists of three types of agents namely turtles, patches and link agents. The overall structure of the proposed agents is shown in Fig. 5. They interact dynamically with each other as well as with conditions of the simulated urban environment. Inter-agent communication relies on shared data to accept or cancel the share of PT vehicles. It is undertaken by broadly depicting a system decision that evolves over time and under urban traffic conditions. Beyond the set of interacting agents, several dynamics related to cities were considered to create a simulated environment for the decision-making process. Such dynamics alternate a random probability distribution or pattern from one value to another following a Markov chains sequences on a discrete-time stochastic process. Hence, discreet instants of sampling time points $\mathrm{t}=\{0,1,2, \ldots\}$, where $\mathrm{t} \in \tau$. In this respect, the future state of the $i^{\text {th }}$ agent at time $\mathrm{t}=\mathrm{T}+1$ that is expressed as $\left\{X_{a i}(t=T+1), X_{a i}(t=T+2), \ldots, X_{a i}\left(t=T+T^{\prime}\right)\right\}_{i=1}^{n}$, where $\operatorname{Tand}^{\prime} \in \tau\left(T<T^{\prime}\right)$. It is based on the previous state in the past of the system $\left\{X_{a i}(t=0), X_{a i}(t=1), X_{a i}(t=2), \ldots, X_{a i}(t=T)\right\}_{i=1^{n}}^{n}$ Thus, agents in the simulation coordinate with each other spreading messages based on a random probability pattern to create

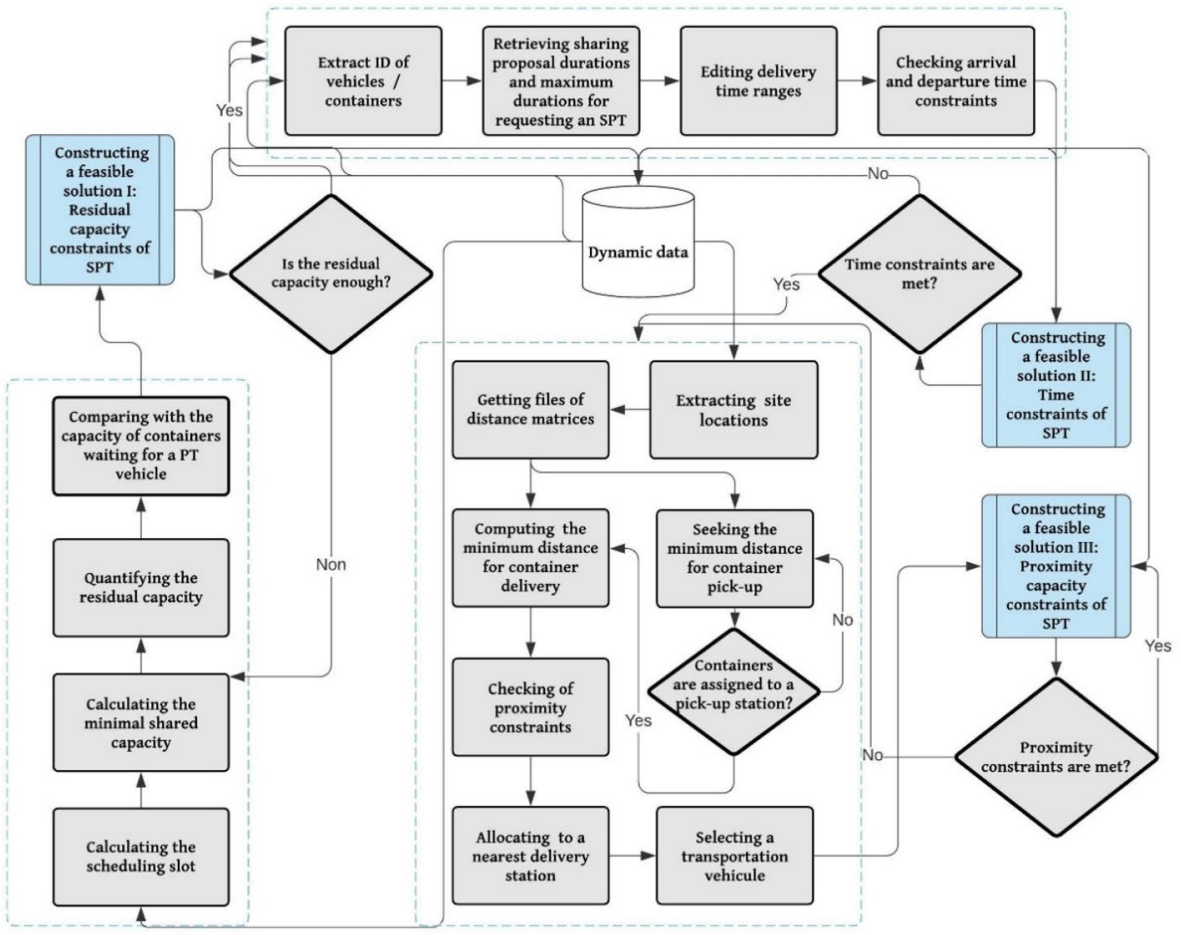

Fig. 6 Flowchart of simulation model architecture 
or not a turtle link (Eq. 2). Their behavior follows stochastic protocols in speed, motions, reactions to simulation environment. That is, the communication features can monitor the status of all other agents and keep track of changes through time.

$$
\begin{aligned}
& P\left(X_{a i}(t=T+1)=x_{T+1} \backslash X_{a i}(t=T)=x_{T}, \ldots, X_{a i}(t=0)=x_{0}\right)_{i=1}^{n} \\
& \quad=P\left(X_{a i}(t=T+1)=x_{T+1} \backslash X_{a i}(t=T)=x_{T}\right)
\end{aligned}
$$

\subsubsection{Matching rules}

In order to establish rules for selecting which a PT vehicle could share an allocated journey, a set of sequential constraints is considered (Fig. 6). We admit $i, i^{\prime}, j, j^{\prime}, e, e^{\prime}, f, f^{\prime}, q \in \mathbb{N}^{*}$ to implement distinctly matching instructions during the next sub-sections.

4.2.3.1 Residual capacity constraints Throughout the day, the residual capacity of a PT vehicle is influenced by a number of factors that make it susceptible to potential uncertainty. Time slots managing is a decisive factor that affects, notably, the residual capacity of a vehicle. Also, logistics demand of the corresponding PT users may affect it during peak times such as holidays, climate change times, work entry and exit times, etc. In this respect, depending on the number of users that onboard users $U_{h_{q-1}}^{\text {onboard }}$, loaded users $U_{h_{q}}^{\text {pick }}$ and/or unloaded users $U_{h_{q}}^{\text {drop }}$ at each station, the system shows the capacity that a PT driver could share during the working time of a journey. At each point of time, residual capacity obtains data from the counter agent and computes the number of users inside the vehicle following an iterative process (Eq. 3-9):

$$
\begin{gathered}
R_{c}^{s p_{0,1}}=C t_{l_{i}}-P_{s p_{0}}^{\text {onboard }}-P_{s p_{1}}^{p i c k}+P_{s p_{1}}^{d r o p}-C_{s p_{0}}^{\text {onboard }}-C_{s p_{1}}^{\text {pick }}+C_{s p_{1}}^{\text {drop }} \\
R_{c}^{s p_{1,2}}=R_{c}^{s p_{0,1}}-P_{s p_{2}}^{p i c k}+P_{s p_{2}}^{d r o p}-C_{s p_{2}}^{p i c k}+C_{s p_{2}}^{d r o p} \\
R_{c}^{s p_{1,2}}=R_{c}^{s p_{1,2}}-P_{s p_{2}}^{p i c k}+P_{s p_{2}}^{d r o p}-C_{s p_{2}}^{p i c k}+C_{s p_{2}}^{\text {drop }} \\
R_{c}^{s p_{2,3}}=R_{c}^{s p_{1,2}}-P_{s p_{3}}^{p i c k}+P_{s p_{3}}^{d r o p}-C_{s p_{3}}^{p i c k}+C_{s p_{3}}^{\text {drop }} \\
R_{c}^{s p_{q-1}, s p_{q}}=R_{c}^{s p_{q-2}, s p_{q-1}}-P_{s p_{q}}^{p i c k}+P_{s p_{q}}^{d r o p}-C_{s p_{q}}^{p i c k}+C_{s p_{q}}^{d r o p} \\
R_{c}^{s p_{q-1}, s p_{q}}=U_{s p_{q-1}}^{o n b o a r d}+U_{s p_{q}}^{p i c k}-U_{s p_{q}}^{\text {drop }} \\
R_{c}^{s p_{q-1}, s p_{q}}=R_{c}^{s p_{q-2}, s p_{q-1}}-U_{s p_{q}}^{p i c k}+U_{s p_{q}}^{\text {drop }}
\end{gathered}
$$

At this stage, dynamic allocation of containers to PT vehicles remains unachievable in the case that the associated seats are busy respecting the specific threshold. Thus, the model decides against the state of the system depending on the residual capacity of the distribution patterns over the scheduling time and under stochastic traffic conditions. 
Formerly, based on the residual capacity, a vehicle $l_{i}$ is either shared or not as per the decision 0-1 variable $D \_s h_{l i}^{\tau}\left(R_{c}^{h_{q-1, q}}\right)$ (Eq. 10). The PT vehicle shall be of appropriate capacity to load demand under shared capacity conditions (Eq. 11).

$$
\begin{gathered}
D \_s h_{l i}^{\tau}\left(R_{c}^{h_{q-1, q}}\right)=\left\{\begin{array}{l}
0, R_{c}^{h_{q-1, q}} \leq M S C_{l i} \\
1, R_{c}^{h_{q-1, q}}>M S C_{l i}
\end{array}\right. \\
C_{c} \sum_{C_{i^{\prime}} \in C} C_{i^{\prime}} \leq R_{c}^{h_{q-1, q}}
\end{gathered}
$$

4.2.3.2 Time constraints A cyclic timetable is commonly used to generate private and PT vehicles of which includes freight forwarding in order to attain reduced delays (Fig. 7). For each vehicle $l_{i} \in L$ with a significant residual capacity, the model evaluates whether time constraints are fulfilled taking into account scheduling, departure and arrival of containers $c_{i^{\prime}} \in C$.

The length of time for scheduling assignments of containers to vehicles is dynamic through time. Each container waits for a PT vehicle before reaching the nearest station if a suitable journey is found among segments of two successive stations.

$$
\begin{gathered}
t_{D} \leq M T D_{c_{i^{\prime}}} \\
d t_{l_{i}}-a t_{l_{i}} \geq a t_{c_{i^{\prime}}^{\prime}}^{\prime}-d t_{l_{i}}^{\prime} \\
d t_{l_{i}}^{\prime}-d t_{c_{i^{\prime}}}^{\prime} \leq d t_{c_{i^{\prime}}}-a t_{c_{i^{\prime}}} \\
a t_{l_{i}} \geq a t_{c_{i^{\prime}}^{\prime}}^{\prime} \\
d t_{c_{i^{\prime}}} \leq d t_{l_{i}}^{\prime} \\
d t_{c_{i^{\prime}}}>a t_{l_{i}}^{\prime}
\end{gathered}
$$

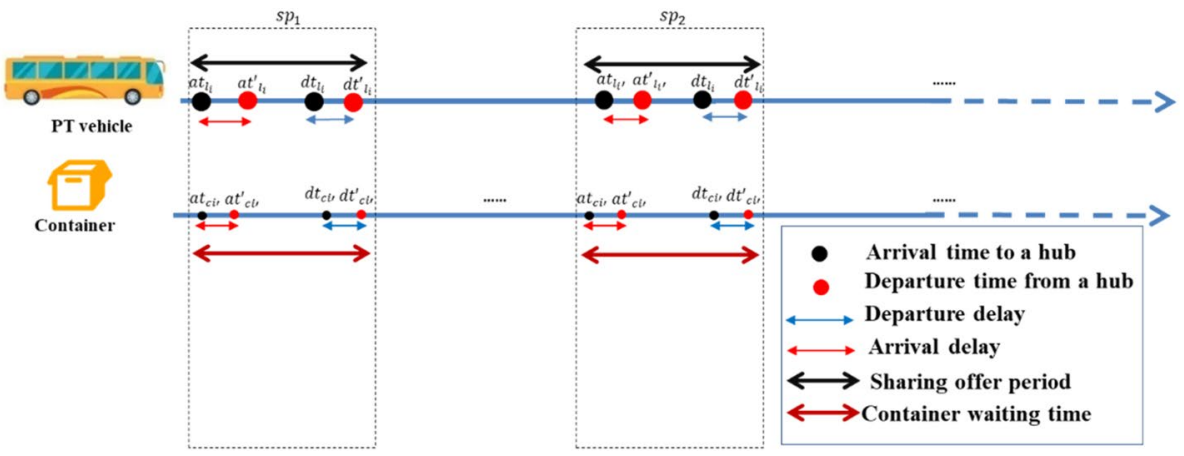

Fig. 7 Time windows included in the simulation model 
For all PT vehicles, the driver opens doors only after the pick-up and drop-off of passengers, which imposes potential delays in arrival/departure times. Thus, the integrated schedule embeds the time frame for loading containers (sharing proposal) from the lasted arrival time of the PT vehicle until the lasted time of its departure $\left[a t^{\prime}{ }_{l_{i}} ; d t^{\prime}{ }_{l_{i}}\right]$. For containers, the maximum duration for requesting a shared PT is considered before its lasted departure $\left[a t_{c_{i^{\prime}}}, d t^{\prime}{ }_{c_{i^{\prime}}}\right]$. A container can be loaded by a PT vehicle if the date of its delivery time is less than the allowed maximal time of delivery. In this respect, the lasted arrival time of a container shall not exceed the period starting from the earliest arrival time of a PT vehicle until the end of the sharing proposal (Eq. 13). A PT vehicle meets the transport demand of a container after container waiting time. Otherwise, it leaves the station using a private vehicle (Eq. 14). To ensure that containers arrive before PT, the arrival time of a PT vehicle does not exceed the lasted arrival time of containers (Eq. 15). Likewise, the lasted departure time of a PT vehicle is longer or equal to the departure time of the candidate container (Eq. 16). However, the earliest departure time of the container must not exceed the lasted arrival time of the PT vehicle (Eq. 17).

4.2.3.3 Proximity constraints In addition, the simulation model aims at minimizing the distance deviation that can result when providing SPT alternative to ship urban freight. For this reason, the end customer can be delivered directly if he is located closer to the station by following a continuous path $P t_{l i}^{c i^{\prime}}$ from the origin station $s p_{l i}^{o_{c i^{\prime}}}$ to the destination station

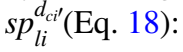

$$
P t_{l i}^{c i^{\prime}}=\left[s p_{l i}^{o} o^{c i^{\prime}} s p_{l i}^{d_{c i^{\prime}}}\right] / P t_{l i}^{c i^{\prime}} \in P t
$$

For each $l_{i} \in L$, the associated stations $\mathrm{sp}_{l i}$ change statute through time from recipient to dispatcher except the original and final stations. At $t \in \tau_{i}$, stations are partitioned into two sets, namely, the departure stations $s p_{l i}^{o}$ and the destination stations $s p_{l i}^{d}$ (Eq. 19):

$$
s p_{l i}=s p_{l i}^{o} U s p_{l i}^{d}
$$

As shown in Eq. 20, such routing path of a container $c_{i}$ is composed of $k$ segments as $\aleph_{j}=\left[s p_{l i}^{d_{j}} s p_{l i}^{d_{j+1}}\right]$, where $s p_{l i}^{d_{j}}$ is the current destination and $s p_{l i}^{d_{j+1}}$ the future one:

$$
\overrightarrow{s p_{l i}^{d}}=\sum_{j=1}^{k-1} \vec{\aleph}_{j} ; \forall l_{i} \in L
$$

Sharing the residual capacity of a PT vehicle could often increase the number of trip segments required for freight to reach its destination. In order to prevent such a deviation problem and thus delivery delays, two additional setups are involved including the maximum deviation distance between the origin (hub/shop) of a container and pick-up station as well as the maximum distance between delivery station towards the end customer (hub/ shop). Accordingly, the model constructs several files of distance matrixes to assign dynamically freight containers to the adequate site and transportation system. In the pickup stage, freight to be transported will be either consolidated in a hub or alternatively located in its origin node, assuming that the origin hub $h_{C_{i^{\prime}}}$ and the origin shop $o_{c_{i^{\prime}}}$ of a container $c_{i^{\prime}}$ from a list of container origins $O_{f}$. Relying on the calculated distance $\theta_{O_{f-} s p_{l i}^{j^{\prime}}}^{o_{i^{\prime}}}$ from the container origin to the associated station, the model relies on a distance minimization 
through calculating the distance matrix. All generated data are stored in a $A p(t)_{O_{f}, s p_{c_{i i}}}^{o_{i^{\prime}}}=\theta_{o_{c_{i^{\prime}} s} s p_{l i}^{o^{\prime}}}$ to assign containers to a pick-up station as presented below, where $O_{f}=\left\{o_{c_{i}^{\prime}} \mid h_{c^{\prime}}\right\}$ :

$$
A p(t)_{O_{f}, s p_{l i}^{o_{i^{\prime}}}}={\stackrel{c}{o_{c_{i^{\prime}}}}}_{h_{c_{i^{\prime}}}}\left[\begin{array}{ccccc}
s p_{l i}^{o_{1}} & s p_{l 1}^{o_{2}} & s p_{l i}^{o_{3}} & \ldots & s p_{l i}^{o_{e^{\prime}}} \\
\theta_{o_{c^{\prime}}-s p_{l i}^{o_{1}}} & \uparrow & \theta_{o_{c_{i}^{\prime}}-s p_{l i}^{o_{3}}} & \ldots & \uparrow \\
\uparrow & \theta_{h_{c_{i}^{\prime}} s p_{l i}^{o_{2}}} & \uparrow & \ldots & \theta_{h_{c_{i}^{\prime}-} s p_{l i}^{o_{e^{\prime}}}}
\end{array}\right]
$$

One of the main decisions in this part of the simulation model is the 0-1 variable $P_{c_{i^{\prime}}, s p_{l i}^{j^{\prime}}}$ indicating the selected pick-up station. If a distance is turned over from the hub to a station then it is no longer available from the origin site. Such distances must be minimized to validate the selection of the pick-up stations (Eq. 21). Thus, a container has to be allocated to only one pick-up station (Eq. 22). When allocating, the distance between the origin and station should not exceed an extra distance as a result of riding in a shared PT vehicle (Eq. 23).

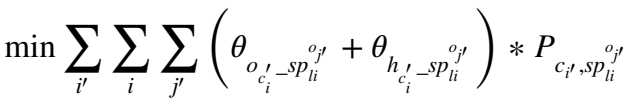

$$
\begin{aligned}
& \sum_{j^{\prime}} P_{c_{i^{\prime}}, s p_{l i}^{o^{\prime}}}=1 ; \forall \\
& P_{c_{i^{\prime}}, s p_{l i}^{o^{\prime}}}=\left\{\begin{array}{l}
1, \theta_{o_{c_{i}^{\prime}-} s p_{l i}^{o_{j^{\prime}}}} \leq \rho \\
0, \theta_{o_{c_{i}^{\prime}-s} s p_{l i}^{j^{\prime}}}>\rho
\end{array}\right.
\end{aligned}
$$

The shared vehicle unloads the goods at the nearest station by reconsidering the residual capacity constraints at all times. In the delivery stage, a distance matrix $A d(t)_{s p_{l i}, D_{f^{\prime}}}=\delta_{s p_{l i}^{d_{j}}-s_{c_{i}^{\prime}}{ }^{\prime}} D_{f^{\prime}}=\left\{s_{c i^{\prime}} \mid h_{c_{i}^{\prime}}\right\}$ needs to be established to calculate the distance between the delivery station and the final recipient node of a container. By considering $D_{f^{\prime}}$ the list of container destinations, the expression of the established destination matrix is as follows:

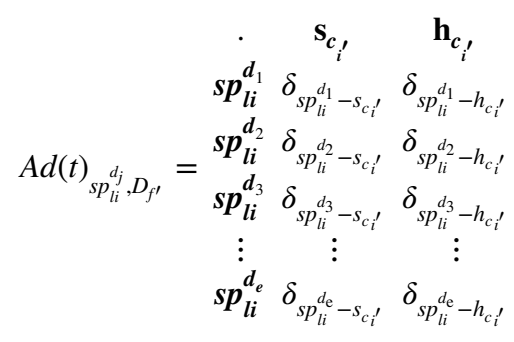

The aim of this step is to manage the delivery process by determining destination stations $s p_{l i}^{d_{j}}$ where containers are to be delivered by a PT vehicle in close proximity to a predefined customer $\mathrm{s}_{c_{i}}$. In this respect, the minimal distances between the delivery stations and shops $d D_{\text {min-dest }}$ or hubs $d D_{\text {min-hub }}$ must not exceed the maximum extra distance $\sigma$ (Eqs. 24 
and 25). Once the decision to share is completed, the model select the best delivery location. The matching algorithm restarts a search procedure from the current best solution that are proposed by precedent steps after several search iterations in order to decide whether a PT vehicle could be shared using the decision $0-1$ variable $D_{s h_{l i}}$.

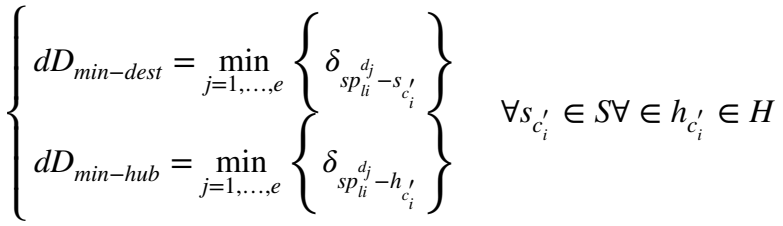

$$
\begin{aligned}
& D_{s h_{l i}}\left(\delta_{s p_{l i}^{d_{j}-s_{c_{i}^{\prime}}}}\right)=\left\{\begin{array}{c}
\text { SelectfromPT, } \min \left\{D_{\text {min-dest }} ; D_{\text {min-hub }}\right\} \leq \sigma \\
\text { SelectfromVmin }\left\{D_{\text {min-dest }} ; D_{\text {min-hub }}\right\} \geq \sigma
\end{array}\right. \\
& P_{c_{i^{\prime}, s}, s p_{l i}^{d_{j}}}=\left\{\begin{array}{l}
\text { Select the nearest station to the end customer, } \quad D_{\text {min-dest }} \leq D_{\text {min-hub }} \\
\text { Select the nearest station to the consolidation hub, } D_{\text {min-dest }}>D_{\text {min-hub }}
\end{array}\right.
\end{aligned}
$$

That is, here are two choices, either to unload the goods near the consolidation hub to which the customer is assigned in order to recover his demand or directly unload near the customer (Eq. 26). The latter alternative is the most preferred if available in order to improve the efficiency of the shared transportation system (Fig. 8).

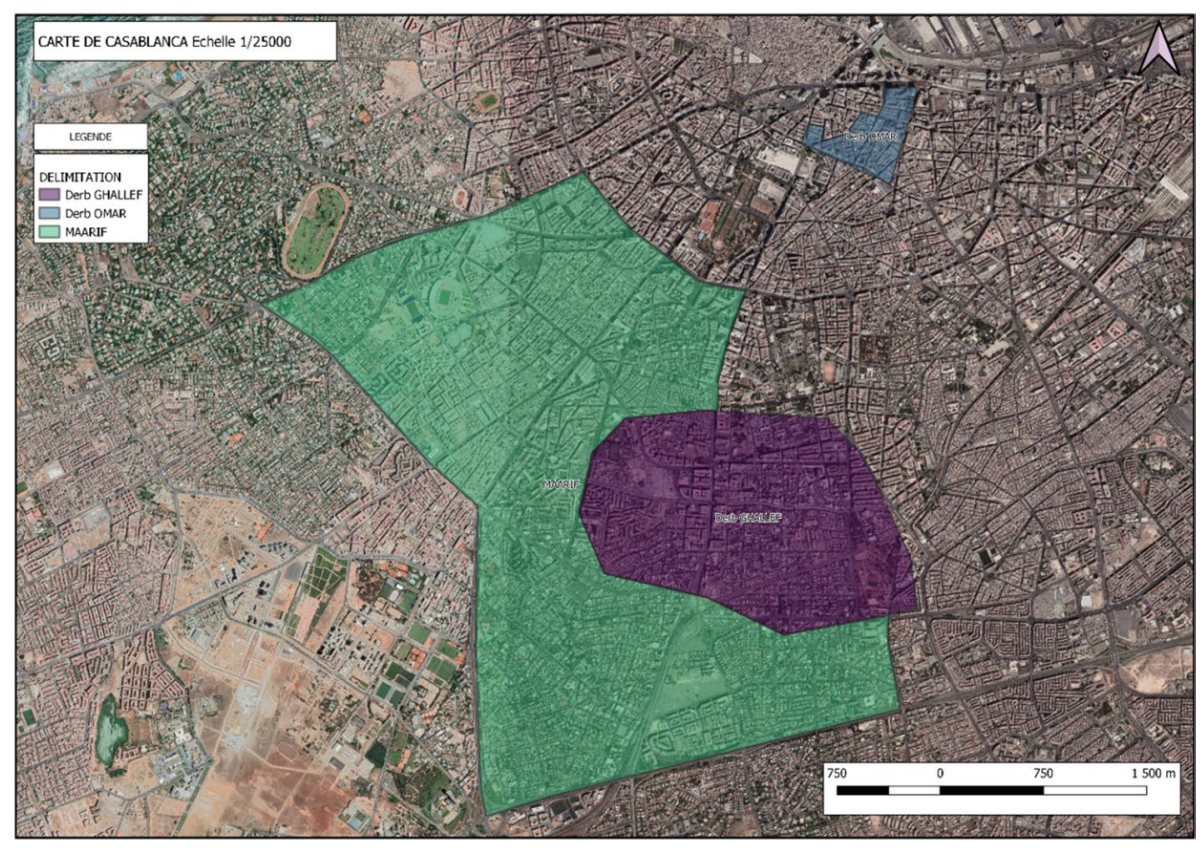

Fig. 8 Zones of experimentation-Casablanca (Morocco) 


\section{Experiments and discussion}

\subsection{Data and implementation}

A real-life case of Casablanca city is conducted in this section across 18 scenarios and two systems of freight transportation to retrieve impacts of implementing an SPT system:

- System 1: Customers are delivered by the conventional transportation system (CFTS).

- System 2: Customers are delivered by SPT vehicles including heterogenous fleets for private delivery if matching rules are not met (SPTS).

The Moroccan Agency for Development of Logistics (MADL) in partnership with VALYANS Consulting in partnership with VALYANS Consulting has conducted field surveys to cope with the data gathering from a complex structure of urban shops supported by a large variety of activity fields (Moroccan Logistics Development Agency 2015a, 2015b, 2015c, 2015d). The investigation of urban territory of Casablanca has been carried out through the analysis of distinct issues on freight transport. It has been a source of valuable data about socio-economic aspects and special characteristics of the urban structure. In this respect, relevant data have been completed on the used logistic infrastructures and related regulations. The survey outcomes have allowed to gain further insights into the demographic situation as well as the various consumption habits of the urban population.

The benchmarking process in this paper relies on the MADL surveys, which have processed separately the assessment of demand volumes to be delivered per zones and time. There are several kinds of merchandises circulating over time slots in the Casablanca zones with different fleets conventional system as MADL reports have explored in depth (Fig. 9). In considering this issue, the selection of appropriate zones has been based on the nature of merchandises that could to be transported with the SPT system. Tree zones (Fig. 8) are selected namely, Marrif, Derb Ghalelf and Derb Omar zones that receive and ship few perishable, heavy and/or bulky demands.

The simulation is initialized by a dynamic and stochastic generating process of agents at a random time included in slots of the day in order to establish dynamic recording of data sets. In this respect, the day is divided into six intervals including [6-8 h],]8-12 h],]12-14
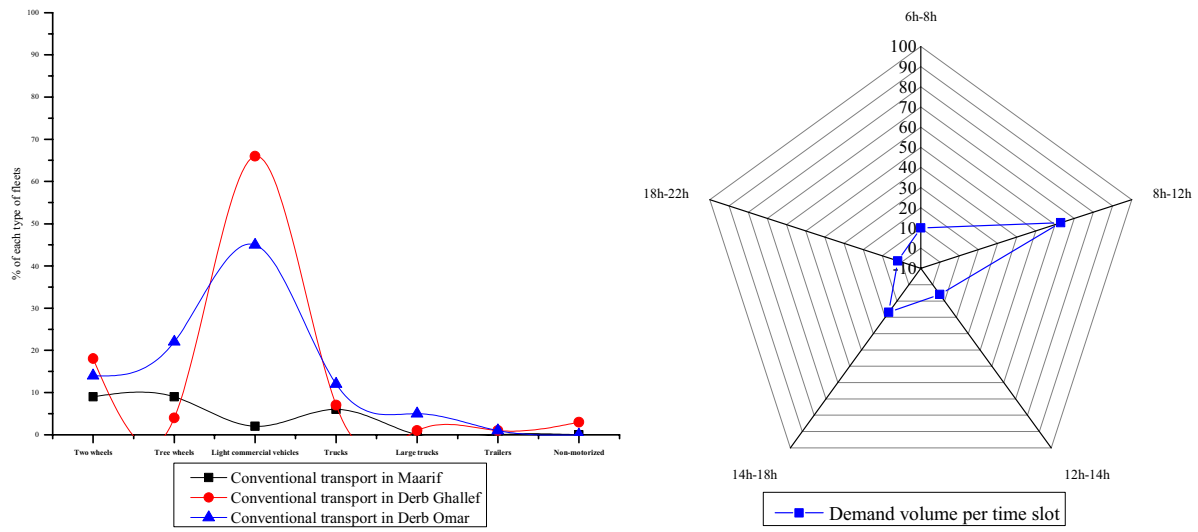

Fig. 9 Rates of demand volumes and used fleets in Casablanca city 
$\mathrm{h}],] 14-18 \mathrm{~h}$ ] and]18-22 h]. The time framework is set using tick-based signal regularly sent to agents for generating responses. Agents interact when they detect a tick, which implies that the length of cycles must be meaningfully fitted. That is, we have simulated the two freight transportation systems over $1440 \mathrm{~min}$, i.e., an average of $24 \mathrm{~h}$ following the ruleof-thumb, which is 5670 ticks in conventional unit of dynamic simulations. Therefore, a number of temporary data sets are raised such as the demand to be satisfied, PT vehicles running in the city which lets us look at the remaining capacity, deadlines, locations, incidents and so on. To run the proposed model, we assume that the daily demand reaches in average 2000 containers per tick. The measurements process of experiments is based on the supposition that the value of PT vehicles is 6 vehicles per tick. Further limitations depend on adjusting the values of $\rho$ and $\sigma$ at $20 \%$ of the distance traveled by the CFTS, which we believe to sustain mainly reduced total kilometers. The establishment of urban environment as well as the two systems SPTS and CFTS are processed within AnyLogic 8.5 ABM toolkits.

\subsection{Results and discussion}

\subsubsection{Evaluation metrics}

In this section, we identify a set of evaluation metrics indicating whether SPT system can provide, especially when involving it as a vital component of the urban system. For focusing attention on what matters most in such systems, key metrics remain an area of large discussion. For example, Q. Long, W. Zhang (2014), Y. Shen et al. (2018), B. Su et al. (2020) have claimed that the validity of shared transportation approaches are often unclear due to the fact that they have been investigated under analytical models that do not consider the whole urban system (Long and Zhang 2014; Shen et al. 2018; Su et al. 2020). These referral guidelines have presented a clear call to provide more measurable and sustainable metrics. Although a limited number of studies that have simulated SPT systems, there is some predefined performance indicators in the literature. D. Fagnant et al. (2014a, 2014b), S. Oh et al. (2020), R. Vosooghi et al. (2019) have used the user waiting time to estimate the sizes of shared fleets needed in order to meet various logistics demands (Fagnant and Kockelman 2014a; Oh et al. 2020; Vosooghi et al. 2019). Hence, the waiting time metric could be a relevant indicator for assessing the performance of SPT in the case of static demand (Fagnant and Kockelman 2014b) and some simulations of dynamic demand (Vosooghi et al. 2019). Keeping the cited metrics, we extend the existing research by including additional metrics, in real time, that we believe to be vital in shared PT systems. The number of containers waiting is the first added metric regarding significant lags in meeting freight transport demand due to the unavailability of residual capacity. Consequently, this could lead to large accumulations of goods waiting in hubs and stations, which is important to provide insights into the system effectiveness. We present, then, a societal metric that explores the number of accidents on urban roads that could be generated through such alternative.

As well, frequent stopping of SPT cars for loading and unloading containers could rise the occupancy ratio of urban roads through illicit parking. In real-time, the rate of parked vehicles is checked in the current investigation for evaluating to what extent shared PT will help to monitor closely effects of system implementation. The extracted data relevant to the objectives of the simulation model is summarized in Table 2. 


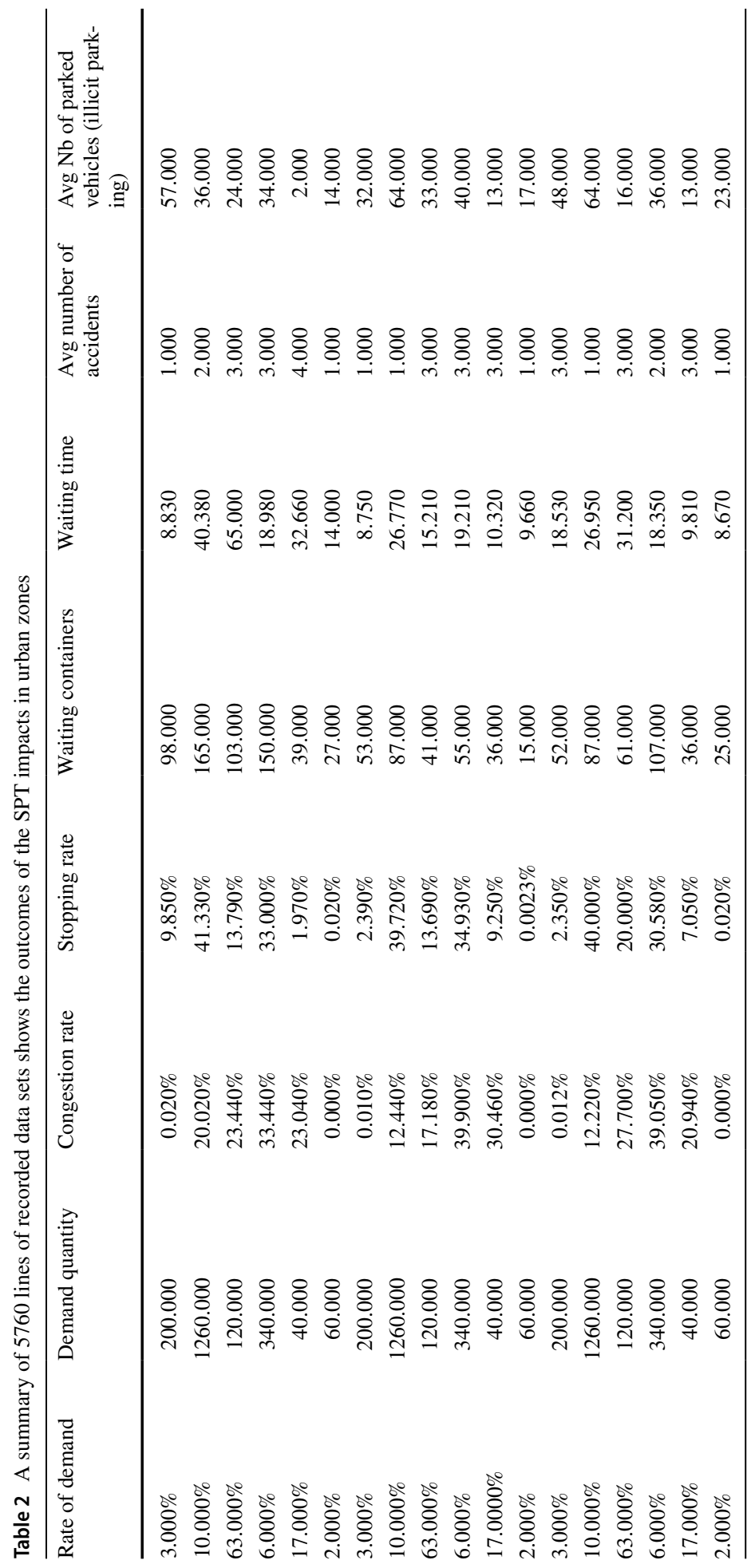




\subsubsection{Numerical results}

Based on the underlying assumptions, matching a given container with a given journey respecting the model's stage constraints could result in a perceived waiting time. Figure 10 shows the achieved outcomes of the average waiting time of a container within the selected zones of Casablanca city. As revealed in the figure, the proposed transport system produces lower values of average waiting time within slots [22-6 h[ and [6-8 h], while the larger ones are observed within]8-12 h] and]12-14 h]. Slots with lower waiting time values are typically characterized by an average congestion rate of $0.011 \%$ and an illegal road occupancy rate of $0.797 \%$, leading to $9.205,13.750,11.375$ ticks of waiting time in Maarif, Derb Ghallef and Derb Omar respectively. However, we note a higher congestion rate in Derb Omar zone with rates of $21.730 \%, 19.960 \%$ in Derb Ghallef and then $14.810 \%$ in Maarif that give averagely a rather high waiting time up to 52.690, 29.075 and 20.990 respectively. However, the lower average container waiting time is reported in the Maarif zone with an average of fewer than 9.200 ticks. In Derb Omar zone, the shortest average waiting time is 11.415 ticks followed by 13.600 ticks in Derb Ghallef zone.

In a further remark, the volume of demand to be carried by SPT system affects the waiting time metric. That is the higher the demand volume, the higher the average waiting time of a container in the location of departure. In terms of the waiting containers metric (Fig. 11), the average number of containers that wait for a PT vehicle after $22 \mathrm{~h}$ until $6 \mathrm{~h}$ is close to 14.000 containers in the Maarif zone. This quantity remains tolerable considering the highest recorded values of 166.000 containers from 8 to $12 \mathrm{~h}$ in the Derb Omar zone as well as 108.000 containers from 14 to $18 \mathrm{~h}$ in the Derb Ghallef zone. Note that between 22 and $6 \mathrm{~h}$, the average number of waiting containers is 27.000 containers in the Derb Omar zone and 25 in Derb Ghallef, which remains a larger quantity with regard to the zone of Maarif. It is quite clear that this metric reveals a significant relationship with the rate of congestion and illicit parking in experimentation zones. For example, the rate of congestion in the Maarif zone is almost null during the time slot [22-6 h [, which justifies the recorded metric trend. While congestion rate reaches $20.020 \%$ in the Derb Omar zone between 8 and $12 \mathrm{~h}$ as well as $39.050 \%$ in Derb Ghallef zone. Furthermore, increasing gradually the value of the average quantity of waiting containers per tick in each time slot is linked to the occupancy rates of the roadway parked cars, which is a major feature of the city of Casablanca. Thus, the variation in the average quantity in Deb Omar and Derb Ghalelf within these hours is explained by the high rates of illicit parking about of $41.370 \%$ and $39.720 \%$ respectively.

According to accident rate, we note that SPTS in the city of Casablanca could minimize the number of daily accidents in urban zones for a few hours but still not keep 0 accidents for a large part of the day comparing with the CFTS (Fig. 12). Averagely, SPTS might decrease the likelihood of accident rate by $18.470 \%$ from 6 to $8 \mathrm{~h}$. During the same slot of time, the accident rate gets smaller in Derb Omar under SPTS against CFTS by about $76.670 \%$. However, accident rate decrease is among all studied zones, including Derb Ghallef zone where this rate decreased progressively from 18 to $22 \mathrm{~h}$ by $8.280 \%$. Generally, the ratio of accidents that are occurred in the Maarif zone under the STPS appears lower than the other zones with an average number of 1 accident per tick of time. Derb Ghallef zone ranks second in terms of the number of accidents generated by the SPT system with less than 2 accidents per tick. Derb Omar zone records almost 3 accidents per tick during the day for providing urban freight forwarding within the 

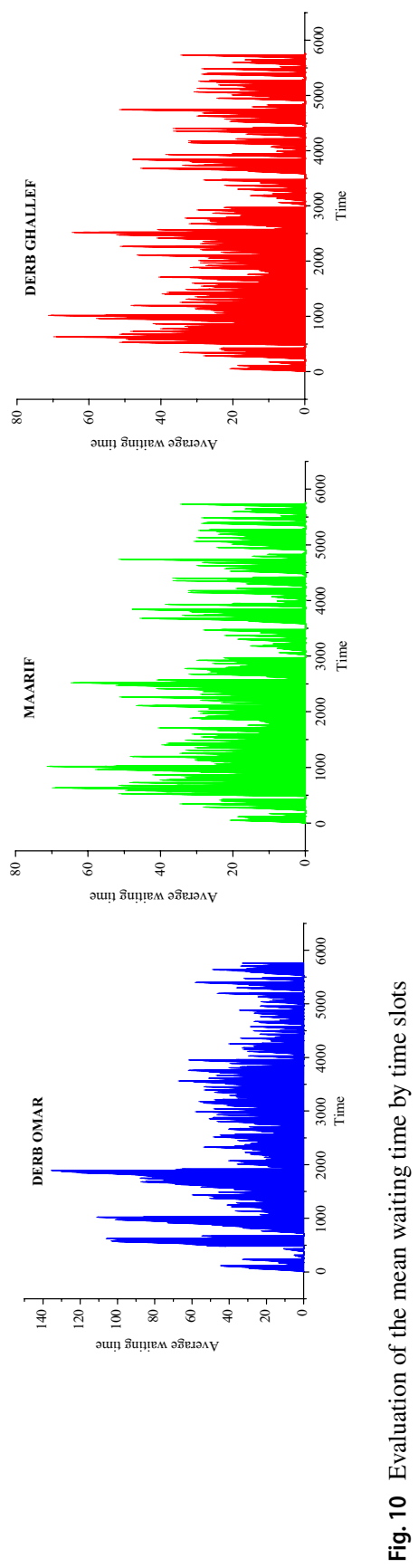

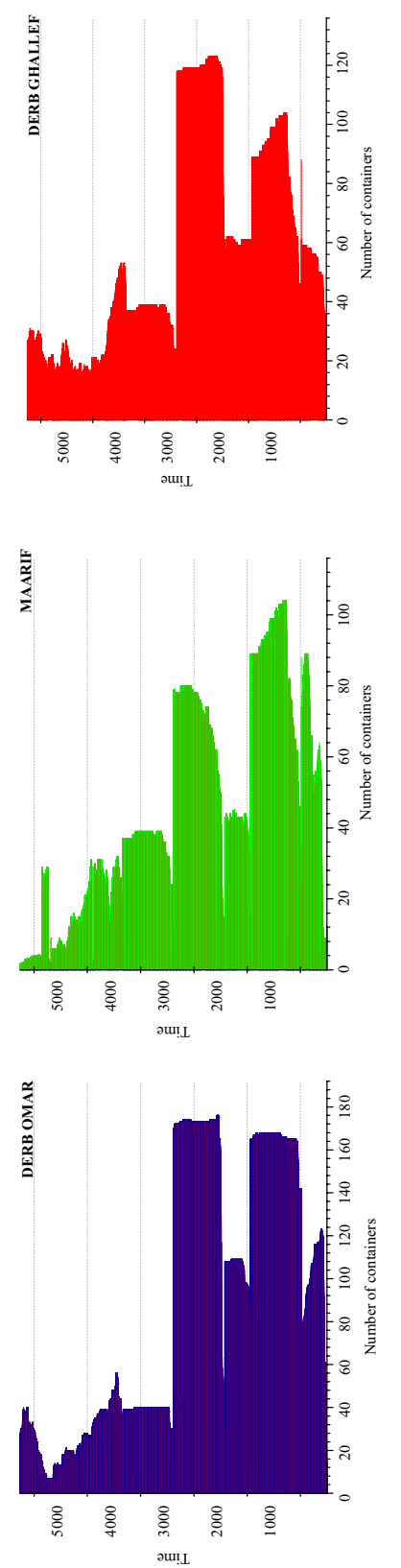

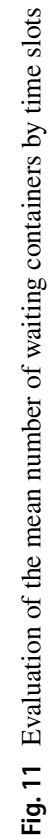



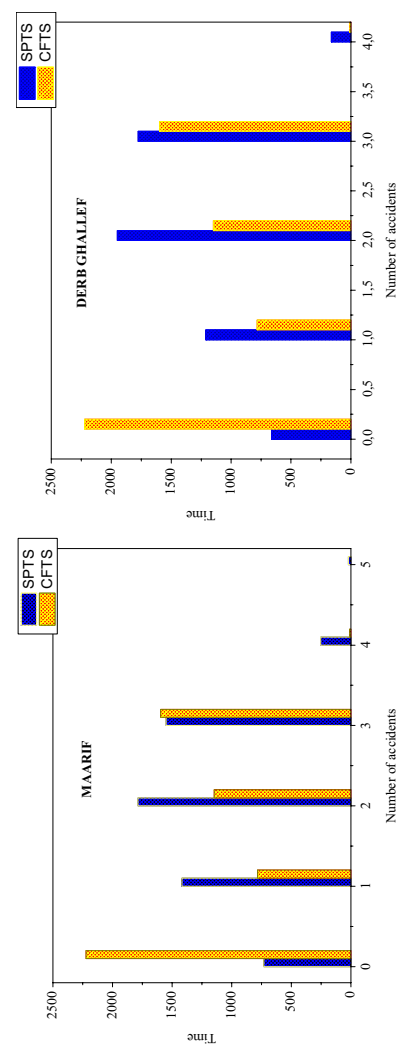

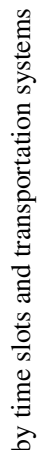

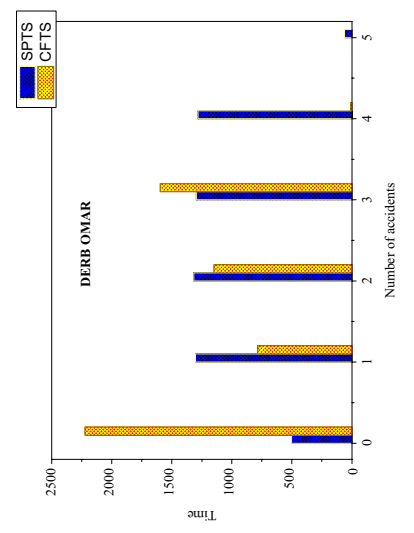

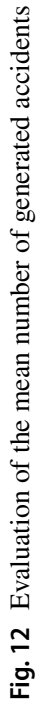


STPS. This means that by adopting the SPTS, the risk of accidents growths typically in all zones namely Maarif, Derb Ghallef, Derb Omar by $26.350 \%, 28.650 \%$ and $40.440 \%$, respectively.

With regard to the rate of occupancy of the roadway by vehicles illicitly parked vehicles, generally, we notice remarkable low obtained values under the SPTS. In the zone of Marrif, we observe a discount rate of $9.400 \%$ from 6 to 8 h (Fig. 13). However, in the region of Derb Ghallef and Derb Omar there is a reduction of $16.070 \%$ and $1.980 \%$ respectively in the number of vehicles using the urban roads for parking in double rows or on reserved paths. From 8 to $12 \mathrm{~h}$, there is a steady reduction of $11.340 \%$ in both zones of Maarif and Derb Ghalleff. A significant decrease is also seen in Derb Omar up to $49.371 \%$. Along with the same token, the time slot from 12 to $14 \mathrm{~h}$ is associated with a decline rate of $95.78 \%$ of illicit parked cars in Maarif zone under the SPTS. In Derb Ghalled, $44.440 \%$ of illegally parked cars are removed versus $60.000 \%$ in Derb Omar. Nonetheless, regarding the duration $14 \mathrm{~h}$ to $18 \mathrm{~h}$, in Maarif zone, it is pointed out that there is a diminution of $92.860 \%$ while this ratio in the other zones remains susceptible to increase in Derb Ghallef with $67.400 \%$ and $79.950 \%$ in Derb Omar. In addition, from 18 to $22 \mathrm{~h}$, parked vehicles in urban roads reached an evolution of $81.560 \%$ in Maarif and Derb Ghallef against $20.050 \%$ in Derb Omar. After $22 \mathrm{~h}$, traffic in the all zones becomes more smoother under CFTS. The SPTS adds per tick an average of 15.000, 22.0000 and 17.0000 vehicles parked on urban road of Derb Omar zone, Derb Ghallef and Maarif.

The simulation results highlight traffic impacts of SPTS through the set of key performance metrics with the aim of encouraging or reminding stockholders to support SPT systems within city core. In order to analyze how these key metrics influence transport policies to guide shared PT implementation, we first extract output samples by means of varying parameter setting. With no hypothesizes on relationship structure, non-parametric rank correlation $r_{s}$ between the observations and the configured parameters is helpful for computing significance weights of discrete data of $n$ observations. In this respect, considering $R\left(x_{i} / y_{i}\right)$ are the ranks and $\overline{R(x / y)}$ are the mean ranks, the formula of $r_{s}$ is given by the Eq. 27.

$$
r_{s}=\frac{\frac{1}{n} \sum_{i=1}^{n}\left(\left(R\left(x_{i}\right)-\overline{R(x)}\right) \cdot\left(R\left(y_{i}\right)-\overline{R(y)}\right)\right)}{\sqrt{\left(( \frac { 1 } { n } \sum _ { i = 1 } ^ { n } ( R ( x _ { i } ) - \overline { R ( x ) } ) ^ { 2 } ) \cdot \left(\left(\frac{1}{n} \sum_{i=1}^{n}\left(R\left(y_{i}\right)-\overline{R(y)}\right)^{2}\right)\right.\right.}}
$$

In analyzing the metric influence on output response, it is important to report that the metric has the strongest impact on the SPT in Casablanca zones. For instances, the number of waiting containers is primarily related to illegal parking of cars in urban roads that reduce traffic speed and time delay of cargo transshipment. This is why the weight of volume demand to be transshipped is in addition considered relevant factor in increasing the number of waiting containers per time unit. Results show that PT stopping remains the most relevant factor when evaluating metrics of the number of waiting containers and waiting time of demand by rates of $82.440 \%$ and $62.580 \%$, respectively. Such a waiting containers metric is significantly affected by the volume of demand to transport per time slot by a rate of $78.140 \%$. Under SPT, traffic congestion is the main factor to consider in managing PT with a rate of $65,690 \%$ in order to reduce potential accidents. However, demand volume could increase the on-street illegal parking metric by $90.070 \%$. More detailed results are presented below. 


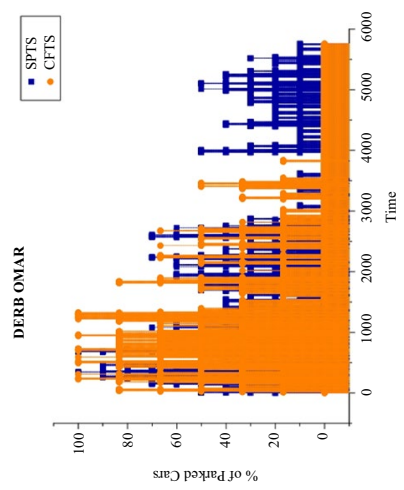

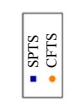
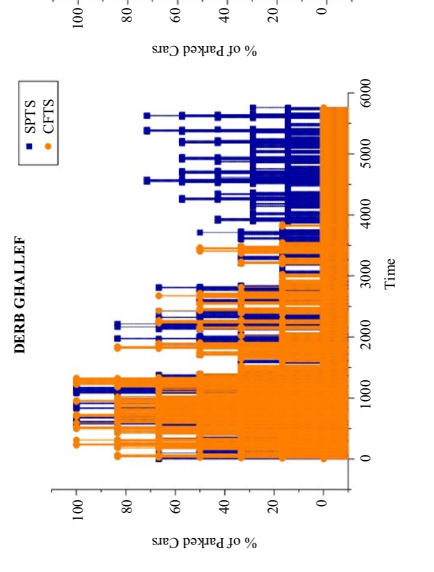

$\frac{\frac{1}{x}}{\frac{x}{2}}$

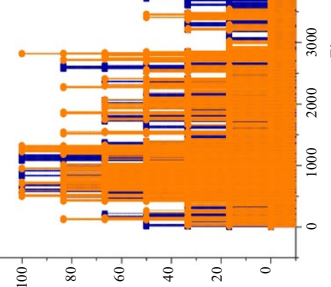

-

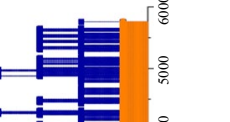

$m$

훈 
The impact of the rate of parked cars is also severe in terms of waiting time of freight, with traffic logging of road networks, which could result in widespread degradation of SPT systems. However, an incremental progress of congestion rate in the main roads could relatively have ultimate impacts on rising accident rate under SPTS, which could cause disruptive changes. The volume of demand over the day is deeply having an impact on all zones of Casablanca including the rate of illicit parking in the city. In addition, the rate of illicit parking in the city is impacted positively by the rate of stoppage of PT vehicles in order to load/unload deliveries.

These reflections, together with the analysis per segment for inspecting simulation purposes prior to implementation, show changes in reacting behavior of Casablanca's zones against the proposed system (Fig. 14). Within a simulated urban environment, Derb Ghallef reacted better than Derb Omar by a percentage of $70.090 \%$. Well, the Maarif zone remains advantageous than Derb Ghallef to conduct such transport policies by $29.900 \%$. Therefore, the Marrif zone performs better than Derb Omar by a ratio up to $100.000 \%$.

On time slots basis, the]18-22 h] slot is expected to minimize the negative impacts on the urban area than]22-6 h [ with a rate of $0.360 \%, 10.770 \%$ than] $12-14 \mathrm{~h}$ ] and $16.200 \%$ than [6-8 h]. This time slot keeps responding better than] $14-18 \mathrm{~h}$ ] with $29.190 \%$ in the setup frame as well as with $99.990 \%$ than] $8-12 \mathrm{~h}$ ]. Nevertheless, the slot] $22-6 \mathrm{~h}$ [ could be better than]12-14 h] with a ratio of $10.400 \%$ as well as than [6-8 h] with a ratio of $15.830 \%$. The so-mentioned time interval is more favorable than]14-18 h] with $28.820 \%$ and is still more valuable for experimenting PT's shared transportation than]8-12 h] with $99.610 \%$. In addition, the hours included in]12-14 h] fits well with freight transport by SPT than [6-8 h] with a limited rate of $5.430 \%, 18.420 \%$ than] $14-18 \mathrm{~h}$ ] and $89.210 \%$ than]8-12 h]. Hence, the residual capacity of the PT during [6-8 h] could be suitably exploited during] $8-12 \mathrm{~h}$ ] with a ratio of $83.790 \%$ as well as with a rate of $12.990 \%$ within]14-18 h] time interval. Compared to]8-12 h], the time interval]14-18 h] remains better with a rate of $70.790 \%$.

As well, results (Fig. 15) show that PT stopping remains the most relevant factor when evaluating metrics of the number of waiting containers and waiting time of demand by rates of $82.440 \%$ and $62.580 \%$, respectively. Such a waiting containers metric is significantly affected by the volume of demand to transport per time slot by a rate of $78.140 \%$. Under SPT, traffic congestion is the main factor to consider in managing PT with a rate of $65,690 \%$ in order to reduce potential accidents. However, demand volume could increase the on-street illegal parking metric by $90.070 \%$.

\subsubsection{Discussion}

This paper has investigated two kinds of urban freight transportation, namely the conventional system and SPT system in terms of passengers and freights. This SPT system is assumed to receive economic and ecologic benefits to be derived from the use of the untapped residual capacity of PT. However, before discussing benefits, it is important to study what the system may entail for urban traffic and road safety. In this section, we discuss the expected impacts that such system upgrades could provide with regard to the whole urban system.

5.2.3.1 Bridging the gap with traffic safety and congestion Restricted empirical evidence exists concerning the assessment of SPT (passengers and freights) interactions with the urban system components. In paper (Trentini and Malhene 2012), researchers have pre- 

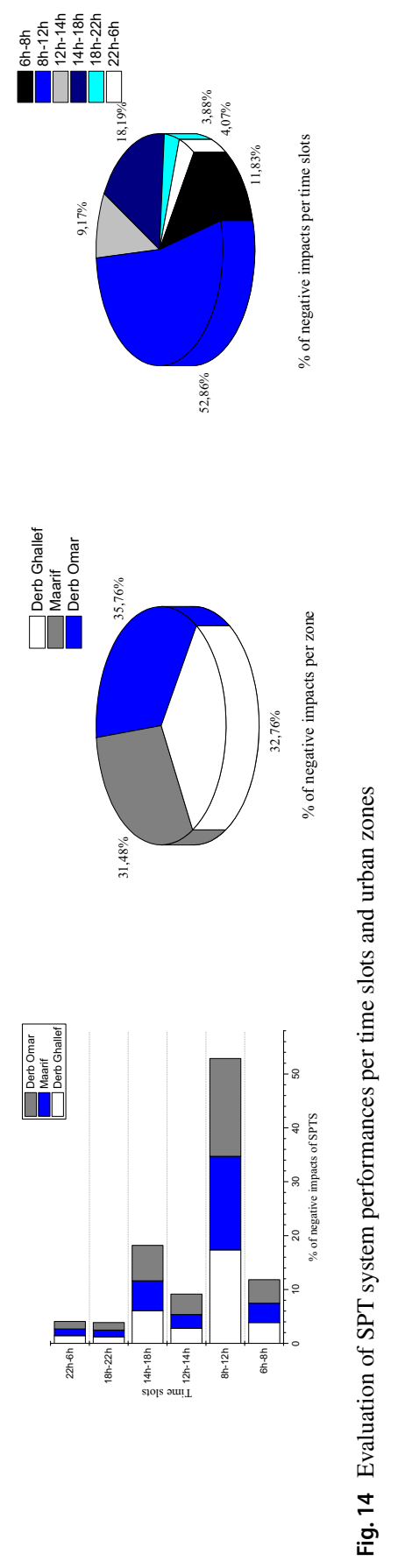
Fig. 15 Impact weight of each evaluation metric on the performance of SPT system

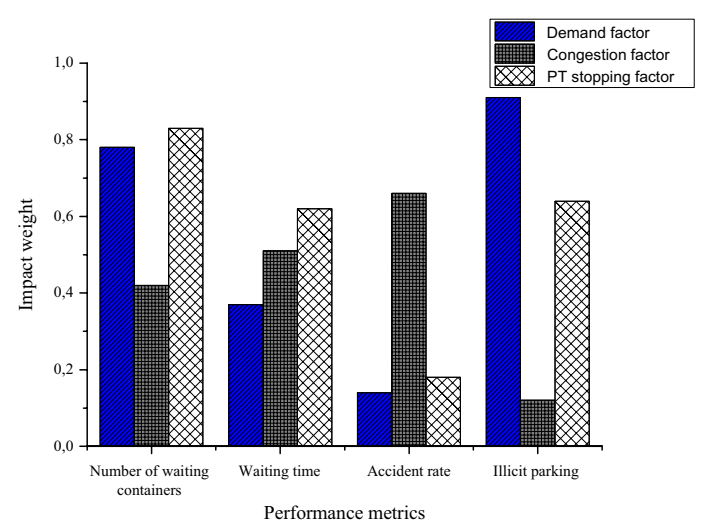

sented a theoretical investigation reporting the two-flow coexisting in urban SPT systems and indicated that they might create a set of social issues. The evoked remarks have recommended sustaining passengers and goods cohabitation in SPT systems under the specific characteristics of each city center. However, city characteristics are typically drawn from heterogeneous zones with various effects on their social, economic and ecologic patterns (Ouadi et al. 2020a). In this respect, it has been shown that the crossings with the highest frequency of collisions have been detected in specific urban zones (Chadwick et al. 2014). The reason for such a statement is probably related to the fact that the risk of exposure is more likely to be significant in zones located in the heart of the city than ones located in the outskirts. The so-mentioned notices could affect practically the achieved measurements of financial and energetic performances. For example, the rate of loaded containers in shared vehicles of PT as a key metric (Masson et al. 2017) has to be treated correspondingly with respect to logistics demand and supply uncertainty. In practice, the uncertainty of residual capacity and user demand makes it difficult to estimate exactly loaded freight amounts to sustain enhanced trust in SPT dimensioning and performance. In relation to the case of non-use of shared transport, energy consumption and pollutant emissions are expected to increase in some zones and lead to the reverse in some others, depending on the rate of congestion and the subsequent externalities (Yu et al. 2020). Such financial, energetic and ecological benefits should not adversely affect risk prevention policies. Disrupting the passenger service quality is among the main matter requires strengthened risk management. In making shared use of PT, the prevention efforts have to be increased for preventing associated risk to generate fatal or severe injuries as well as additional road occupancy over time and location level. The risk of SPT could approximately in the same array as the risk of sharing bicycles in the potential crash as long as they constitute two urban transit systems. According to the findings of the paper (Fishman and Schepers 2016), a slower speed extends the time for users to avoid accidents occurring within shared bicycles transportation system. For PT, serious PT crashes could be related to weekend times, lack of a median road, unfavorable terrain (curved, damp and bumpy roads), collisions with pedestrians and drunk driving. Equally, minibuses tend to exhibit fewer severe accidents owing to various factors, including the absence of road shoulders, accidents at intersections, the presence of traffic control and the types of collisions (Sam et al. 2018).

5.2.3.2 Supporting the decision-making process In literature, evaluation processes of SPT systems in terms of passengers and cargo have highlighted many benefits and future 
implementation prospects within cities. However, there are some observed disadvantages that have impacted the system outcomes and decision making of stakeholders. Although theoretical and conceptual frameworks have provided an important base of knowledge, they have not could tackle the overall challenges and have been remaining unable to deliver insights to the entire understanding of system interaction patterns (Trentini et al. 2011). In addition, while the comparative surveys have developed the proposed policies and managerial approaches of sharing PT with urban freight, they have had a limited impact on decision-making focusing on traffic congestion and road safety (Bruzzone et al. 2021). The aim of introducing such social indicators is to enhance the ability of SPT systems to attract more attention from stakeholders, gain additional market share and save even more resources as sustainability assets. Physical models that are based on systemic agent relationships could provide more detailed data as well as add further city components for more convenience and higher efficiency (Behiri et al. 2018). Furthermore, these models make it possible to integrate statistics based on accredited institutional reports in providing dynamic data, often difficult to gather. This will then be useful to predict the manners in which this system would behave within a more realistic experimentation environment. For example, if AMDL and other important players in urban logistics notice the achieved SPT performances compared mainly to the conventional system, it will be able to explore how existing arrangements are navigating the disruption of shared transport. Rather, decision-makers would be empowered to approve or prohibit the sharing of logistics resources within an area and/or during specific time slots (Fatnassi et al. 2015). In harnessing these features, the dynamic simulation involves city players in decision processes by relying on dynamic dashboards, which support realtime management and expected damage mitigation.

\section{Conclusion}

We addressed a viable alternative, namely SPT system to solve some of the urban transportation issues through further integrating freights into PT within cities. In general, cities consist of complex systems of many interactive entities. This research supported this systemic concept in SPT modeling in order to investigate potential impacts on urban traffic as a part of the city system. To depict connections between the scheduled journeys and SPT users, we proposed a generic simulation framework based on reactive agents and stochastic dynamics. Providing such a framework has been justified by the aim to estimate SPT performances based on statistics data retrieved from government institutional surveys.

In this respect, we outlined a set of evaluation metrics to assess potential effects and dynamics that are fewest discussed in the reviewed literature. Evaluation metrics were identified within a sustainable framework representing a universal policy asset. Including container format for freight movements, waiting time of urban cargo aimed to illustrate when and where demand for transportation using SPT is expected to wait longer. System performances and the quantities of waiting containers over time were also interrelated for carrying out a continuous quality of service and user satisfaction. Based on empirical results, implementing safety metrics for shared use of PT would significantly enhance traffic incident management and road safety. Typical examples could include the development of comprehensive regulation devices, increasing signage and visibility, 
identifying speeds and safety seats. Furthermore, the potential effects of the proposed system on traffic fluidity in terms of illicit parked cars were assessed to measure benefits/ disadvantages that might be implied within congested areas.

To help with benchmarking tasks, we modeled the conventional system that is mainly considered a referential frame for quantifying SPT performances and understanding outcome tendencies. An illustrative case study of Casablanca city was treated for urban players interested in the institutional-based studies. Including data issued in the AMDL reports, key findings were achieved. Broadly speaking, Maarif, Derb Ghallef and Derb Omar reacted quite in the same way to the simulated environments. However, Maarif was deemed to be the urban zone with the most advantageous experimentation conditions by averagely $64.950 \%$ than Derb Omar and Derb Ghallef zones. From a time point of view, it was revealed that negatives externalities might be significantly apparent between 8 and $12 \mathrm{~h}$.

With such a quantitative investigation, we do not only aim to bring improvements in urban mobility in Casablanca but also to understand in the broad range the overall social impacts of sharing logistics facilities. From this perspective, performance benchmarking is at the heart of the process of checking the efficiency of shared strategies in urban areas. Thus, players involved in cities and urban mobility might be more inclined to follow the guidance provided to assess the broader scopes of future PT initiatives. Future research is in progress to further improve SPT evaluation process including (1) developing the evaluation indicators by incorporating the satisfaction rate of the two users (passengers and freights), (2) processing the last mile with eco-friendly fleets and (3) investigating the ecological and energetic impact towards more sustainable mobility.

Funding This funding was provided by Centre National pour la Recherche Scientifique et Technique.

\section{References}

Aloi, A., Alonso, B., Benavente, J., Cordera, R., Echániz, E., González, F., Ladisa, C., Lezama-Romanelli, R., López-Parra, Á., Mazzei, V., Perrucci, L., Prieto-Quintana, D., Rodríguez, A., Sañudo, R.: Effects of the COVID-19 lockdown on urban mobility: empirical evidence from the City of Santander (Spain). Sustainability 12(9), 3870 (2020). https://doi.org/10.3390/su12093870

Anand, N., van Duin, R., Tavasszy, L.: Carbon credits and urban freight consolidation: an experiment using agent based simulation. Res. Transp. Econ. (2019). https://doi.org/10.1016/j.retrec.2019.100797

Andersson, P.-A., Hermansson, А., Tengvald, E., Scalia-Tomba, G.-P.: Analysis and simulation of an urban bus route. Transp. Res. Part A General 13(6), 439-466 (1979). https://doi.org/10.1016/0191-2607(79) 90007-4

Baldacci, R., Battarra, M., Vigo, D.: Routing a Heterogeneous Fleet of Vehicles. In: Golden, B., Raghavan, S., Wasil, E. (eds.) The Vehicle Routing Problem: Latest Advances and New Challenges, pp. 3-27. Springer, US (2008)

Baldacci, R., Battarra, M., Vigo, D.: Valid inequalities for the fleet size and mix vehicle routing problem with fixed costs. Networks 54(4), 178-189 (2009). https://doi.org/10.1002/net.20331

Behiri, W., Belmokhtar-Berraf, S., Chu, C.: Urban freight transport using passenger rail network: scientific issues and quantitative analysis. Transp. Res. Part E Logist. Transp. Rev. 115, 227-245 (2018). https://doi.org/10.1016/j.tre.2018.05.002

Beirigo, B.A., Schulte, F., Negenborn, R.R.: Integrating people and freight transportation using shared autonomous vehicles with compartments. IFAC-PapersOnLine 51(9), 392-397 (2018). https://doi. org/10.1016/j.ifacol.2018.07.064

Berggren, U., Brundell-Freij, K., Svensson, H., Wretstrand, A.: Effects from usage of pre-trip information and passenger scheduling strategies on waiting times in public transport: an empirical survey based on a dedicated smartphone application. Public Transp. (2019). https://doi.org/10.1007/ s12469-019-00220-1 
Bruzzone, F., Cavallaro, F., Nocera, S.: The integration of passenger and freight transport for first-last mile operations. Transp. Policy 100, 31-48 (2021). https://doi.org/10.1016/j.tranpol.2020.10.009

Buchanan, C.A., Charara, M., Sullivan, J.L., Lewis, G.M., Keoleian, G.A.: Lightweighting shipping containers: Life cycle impacts on multimodal freight transportation. Transp. Res. Part d: Transp. Environ. 62, 418-432 (2018). https://doi.org/10.1016/j.trd.2018.03.011

Bueno-Cadena, C.E., Munoz, J.C., Tirachini, A.: An analytical model for controlling disruptions on a metro line. Transp. Res. Part C Emerg. Technol. 117, 102669 (2020). https://doi.org/10.1016/j.trc.2020. 102669

Cao, E., Lai, M., Yang, H.: Open vehicle routing problem with demand uncertainty and its robust strategies. Expert Syst. Appl. 41(7), 3569-3575 (2014). https://doi.org/10.1016/j.eswa.2013.11.004

Chadwick, S.G., Zhou, N., Saat, M.R.: Highway-rail grade crossing safety challenges for shared operations of high-speed passenger and heavy freight rail in the U.S. Saf. Sci. 68, 128-137 (2014). https://doi. org/10.1016/j.ssci.2014.03.003

Chand, P., \& Mohanty, J. R. (n.d.). A Multi-objective Vehicle Routing Problem using Dominant Rank Method. International Journal of Computer Application, 29-34.

Chandra, S., Naik, R.T., Jimenez, J.: Crowdsourcing-based traffic simulation for smart freight mobility. Simul. Model. Pract. Theory 95, 1-15 (2019). https://doi.org/10.1016/j.simpat.2019.04.004

Dablanc, L.: Goods transport in large European cities: difficult to organize, difficult to modernize. Transp. Res. Part A Policy Pract. 41(3), 280-285 (2007). https://doi.org/10.1016/j.tra.2006.05.005

Dablanc, L.: Urban goods movement and air quality policy and regulation issues in European Cities. J. Environ. Law 20(2), 245-266 (2008)

de Bok, M., Tavasszy, L.: An empirical agent-based simulation system for urban goods transport (MASSGT). Procedia Comput. Sci. 130, 126-133 (2018). https://doi.org/10.1016/j.procs.2018.04.021

de Grange, L., Troncoso, R., González, F.: An empirical evaluation of the impact of three urban transportation policies on transit use. Transp. Policy 22, 11-19 (2012). https://doi.org/10.1016/j.tranpol.2012. 04.003

DeliveryMin, H.: The multiple vehicle routing problem with simultaneous delivery and pick-up points. Transp. Res. Part A General 23(5), 377-386 (1989). https://doi.org/10.1016/0191-2607(89)90085-X

Deniaud, I., Quiguer, S., Breuil, D., Maguet, P.L., Lecourt, J., Pourcel, C., Ruault, J.-R., Somat, A.: Interoperability dimensions for multimodal mobility management. IFAC Proc. Vol. 45(6), 1529-1536 (2012). https://doi.org/10.3182/20120523-3-RO-2023.00203

Diabat, A., Richard, J.-P., Codrington, C.W.: A Lagrangian relaxation approach to simultaneous strategic and tactical planning in supply chain design. Ann. Oper. Res. 203(1), 55-80 (2013). https://doi.org/ 10.1007/s10479-011-0915-2

Dlugosch O, Brandt T, Neumann D. Combining analytics and simulation methods to assess the impact of shared, autonomous electric vehicles on sustainable urban mobility. Information \& Management. Published online February 2020:103285. doi:https://doi.org/10.1016/j.im.2020.103285

Dondo, R., Méndez, C.A., Cerdá, J.: The multi-echelon vehicle routing problem with cross docking in supply chain management. Comput. Chem. Eng. 35(12), 3002-3024 (2011). https://doi.org/10.1016/j. compchemeng.2011.03.028

El Ouadi, J., Malhene, N., Benhadou, S., Medromi, H.: Strategic zoning approach for urban areas: towards a shared transportation system. Procedia Comput. Sci. 170, 211-218 (2020a). https://doi.org/10.1016/j. procs.2020.03.027

El Ouadi, J., Malhene, N., Benhadou, S., Medromi, H.: Shared public transport within a physical internet framework: reviews, conceptualization and expected challenges under COVID-19 pandemic. IATSS Res. (2021a). https://doi.org/10.1016/j.iatssr.2021.03.001

El Ouadi, J., Errousso, H., Malhene, N., Benhadou, S., Medromi, H.: A machine-learning based hybrid algorithm for strategic location of urban bundling hubs to support shared public transport. Qual. Quant. (2021b). https://doi.org/10.1007/s11135-021-01263-y

El Ouadi, J., Malhene, N., Benhadou, S., Medromi, H.: Support vector machines and k-means to build implementation areas of bundling hubs. Eur. Transp. 83, 1-18 (2021)

El Ouadi, J., Errousso, H., Benhadou, S., Medromi, H., \& Malhene, N. (2020). A Machine-Learning Based Approach for Zoning Urban Area in Consolidation Schemes Context. 2020 IEEE 13th International Colloquium of Logistics and Supply Chain Management (LOGISTIQUA), 1-7. https://doi.org/10. 1109/LOGISTIQUA49782.2020.9353901

Fagnant, D.J., Kockelman, K.M.: The travel and environmental implications of shared autonomous vehicles, using agent-based model scenarios. Transp. Res. Part C Emerg. Technol. 40, 1-13 (2014a). https:// doi.org/10.1016/j.trc.2013.12.001 
Fagnant, D.J., Kockelman, K.M.: The travel and environmental implications of shared autonomous vehicles, using agent-based model scenarios. Transp. Res. Part C Emerg. Technol. 40, 1-13 (2014b). https:// doi.org/10.1016/j.trc.2013.12.001

Fallahi, A.E., Prins, C., Wolfler Calvo, R.: A memetic algorithm and a tabu search for the multi-compartment vehicle routing problem. Comput. Oper. Res. 35(5), 1725-1741 (2008). https://doi.org/10. 1016/j.cor.2006.10.006

Fancello, G., Carta, M., Serra, P.: Data envelopment analysis for the assessment of road safety in urban road networks: a comparative study using CCR and BCC models. Case Stud. Transp. Policy 8(3), 736-744 (2020). https://doi.org/10.1016/j.cstp.2020.07.007

Fatnassi, E., Chaouachi, J., Klibi, W.: Planning and operating a shared goods and passengers on-demand rapid transit system for sustainable city-logistics. Transp. Res. Part B Methodol. 81, 440-460 (2015). https://doi.org/10.1016/j.trb.2015.07.016

Fishman, E., Schepers, P.: Global bike share: what the data tells us about road safety. J. Safety Res. 56, 41-45 (2016). https://doi.org/10.1016/j.jsr.2015.11.007

FlexibleArchetti, C., Fernández, E., Huerta-Muñoz, D.L.: A two-phase solution algorithm for the Flexible Periodic Vehicle Routing Problem. Comput. Oper. Res. 99, 27-37 (2018). https://doi.org/10.1016/j. cor.2018.05.021

Gansterer, M., Hartl, R.F.: Shared resources in collaborative vehicle routing. TOP 28(1), 1-20 (2020). https://doi.org/10.1007/s11750-020-00541-6

Gkiotsalitis, K., Stathopoulos, A.: Demand-responsive public transportation re-scheduling for adjusting to the joint leisure activity demand. Int. J. Transp. Sci. Technol. 5(2), 68-82 (2016). https://doi.org/10. 1016/j.ijtst.2016.09.004

Gnimpieba, Z.D.R., Nait-Sidi-Moh, A., Durand, D., Fortin, J.: Using internet of things technologies for a collaborative supply chain: application to tracking of pallets and containers. Procedia Comput. Sci. 56, 550-557 (2015). https://doi.org/10.1016/j.procs.2015.07.251

Gonzalez-Feliu, J., Pronello, C., Grau, J.M.S.: Multi-stakeholder collaboration in urban transport: State-ofthe-art and research opportunities. Transport 33(4), 1079-1094 (2018). https://doi.org/10.3846/trans port. 2018.6810

Haghani, A., Jung, S.: A dynamic vehicle routing problem with time-dependent travel times. Comput. Oper. Res. 32(11), 2959-2986 (2005). https://doi.org/10.1016/j.cor.2004.04.013

Hai, D., Xu, J., Duan, Z., Chen, C.: Effects of underground logistics system on urban freight traffic: a case study in Shanghai, China. J. Clean. Prod. 260, 121019 (2020). https://doi.org/10.1016/j.jclepro.2020. 121019

Ho, W., Ho, G.T.S., Ji, P., Lau, H.C.W.: A hybrid genetic algorithm for the multi-depot vehicle routing problem. Eng. Appl. Artif. Intell. 21(4), 548-557 (2008). https://doi.org/10.1016/j.engappai.2007.06.001

Huang, D., Tong, W., Wang, L., Yang, X.: An analytical model for the many-to-one demand responsive transit systems. Sustainability. 12(1), 298 (2019). https://doi.org/10.3390/su12010298

Huang, D., Gu, Y., Wang, S., Liu, Z., Zhang, W.: A two-phase optimization model for the demand-responsive customized bus network design. Transp. Res. Part C Emerg. Technol. 111, 1-21 (2020). https:// doi.org/10.1016/j.trc.2019.12.004

Hwang, H.-S.: An improved model for vehicle routing problem with time constraint based on genetic algorithm. Comput. Ind. Eng. 42(2), 361-369 (2002). https://doi.org/10.1016/S0360-8352(02)00033-5

Inturri, G., Le Pira, M., Giuffrida, N., Ignaccolo, M., Pluchino, A., Rapisarda, A., D’Angelo, R.: Multi-agent simulation for planning and designing new shared mobility services. Res. Transp. Econ. 73, 34-44 (2019). https://doi.org/10.1016/j.retrec.2018.11.009

Kim, G., Ong, Y.-S., Heng, C.K., Tan, P.S., Zhang, N.A.: City vehicle routing problem (City VRP): a review. IEEE Trans. Intell. Transp. Syst. 16(4), 1654-1666 (2015). https://doi.org/10.1109/TITS. 2015.2395536

Laporte, G., \& Nobert, Y. (1987). Exact Algorithms for the Vehicle Routing Problem**The authors are grateful to the Canadian Natural Sciences and Engineering Research Council (grants A4747 and A5486) and to the Quebec Government (FCAC grant 80EQ04228) for their financial support. In S. Martello, G. Laporte, M. Minoux, \& C. Ribeiro (Eds.), North-Holland Mathematics Studies (Vol. 132, pp. 147-184). North-Holland. https://doi.org/10.1016/S0304-0208(08)73235-3

Li, B., Krushinsky, D., Reijers, H.A., Van Woensel, T.: The share-a-ride problem: people and parcels sharing taxis. Eur. J. Oper. Res. 238(1), 31-40 (2014). https://doi.org/10.1016/j.ejor.2014.03.003

Li, P., He, J., Zheng, D., Huang, Y., Fan, C.: Vehicle routing problem with soft time windows based on improved genetic algorithm for fruits and vegetables distribution. Discret. Dyn. Nat. Soc. 2015, e483830 (2015). https://doi.org/10.1155/2015/483830 
Liu, L., Sun, L., Chen, Y., Ma, X.: Optimizing fleet size and scheduling of feeder transit services considering the influence of bike-sharing systems. J. Clean. Prod. 236, 117550 (2019). https://doi.org/10. 1016/j.jclepro.2019.07.025

Liu, C., Kou, G., Zhou, X., Peng, Y., Sheng, H., Alsaadi, F.E.: Time-dependent vehicle routing problem with time windows of city logistics with a congestion avoidance approach. Knowl.-Based Syst. 188, 104813 (2020). https://doi.org/10.1016/j.knosys.2019.06.021

Long, Q., Zhang, W.: An integrated framework for agent based inventory-production-transportation modeling and distributed simulation of supply chains. Inf. Sci. 277, 567-581 (2014). https://doi. org/10.1016/j.ins.2014.02.147

Lu, Y., Lang, M., Sun, Y., Li, S.: A fuzzy intercontinental road-rail multimodal routing model with time and train capacity uncertainty and fuzzy programming approaches. IEEE Access 8, 27532-27548 (2020). https://doi.org/10.1109/ACCESS.2020.2971027

Manser, P., Becker, H., Hörl, S., Axhausen, K.W.: Designing a large-scale public transport network using agent-based microsimulation. Transp. Res. Part A Policy Pract. 137, 1-15 (2020). https:// doi.org/10.1016/j.tra.2020.04.011

Martinez, L.M., Correia, G.H.A., Viegas, J.M.: An agent-based simulation model to assess the impacts of introducing a shared-taxi system: an application to Lisbon (Portugal). J. Adv. Transp. 49(3), 475-495 (2015). https://doi.org/10.1002/atr.1283

Masson, R., Trentini, A., Lehuédé, F., Malhéné, N., Péton, O., Tlahig, H.: Optimization of a city logistics transportation system with mixed passengers and goods. EURO J. Transp. Logist. 6(1), 81-109 (2017). https://doi.org/10.1007/s13676-015-0085-5

Mizutani, J., Fukuda, S.: Issues on modal shift of freight from road to rail in Japan: review of rail track ownership, investment and access charges after the National Railway restructuring. Res. Transp. Bus. Manag. 35, 100484 (2020). https://doi.org/10.1016/j.rtbm.2020.100484

Mommens, K., Lebeau, P., Verlinde, S., van Lier, T., Macharis, C.: Evaluating the impact of off-hour deliveries: an application of the TRansport Agent-BAsed model. Transp. Res. Part d: Transp. Environ. 62, 102-111 (2018). https://doi.org/10.1016/j.trd.2018.02.003

Moosavi, S.M.H., Ismail, A., Yuen, C.W.: Using simulation model as a tool for analyzing bus service reliability and implementing improvement strategies. PLoS ONE 15(5), e0232799 (2020). https:// doi.org/10.1371/journal.pone.0232799

Moroccan Logistics Development Agency, M., \& KINGDOM OF MOROCC. (2015). Etude pour la structuration de la logistique urbaine au MarocMission IV : Etude du cas de Casablanca -Etat des lieux de la logistique urbaine à Casablanca -. VALYANS Consulting

Moroccan Logistics Development Agency, M., \& KINGDOM OF MOROCC. (2015). Etude pour la structuration de la logistique urbaine au MarocMission III : Définition d'une vision à long terme et de plans d'actions à court et moyen termes -Formulation et déclinaison de la vision stratégique - . VALYANS Consulting

Moroccan Logistics Development Agency, M., \& KINGDOM OF MOROCC. (2015). Etude pour la structuration de la logistique urbaine au MarocMission II : Etat des lieux et tendances de la logistique urbaine nationale. VALYANS Consulting

Moroccan Logistics Development Agency, M., \& KINGDOM OF MOROCC. (2015). Etude pour la structuration de la logistique urbaine au MarocMission IV : Etude du cas de Casablanca -Vision et plan d'actions spécifiques à Casablanca pour la structuration de sa logistique urbaine -. VALYANS Consulting

Nealer, R., Matthews, H.S., Hendrickson, C.: Assessing the energy and greenhouse gas emissions mitigation effectiveness of potential US modal freight policies. Transp. Res. Part A Policy Pract. 46(3), 588-601 (2012). https://doi.org/10.1016/j.tra.2011.11.010

Ngoc, A.M., Hung, K.V., Tuan, V.A.: Towards the development of quality standards for public transport service in developing countries: analysis of public transport users' behavior. Transp. Res. Procedia 25, 4560-4579 (2017). https://doi.org/10.1016/j.trpro.2017.05.354

Nguyen-Phuoc, D.Q., Young, W., Currie, G., De Gruyter, C.: Traffic congestion relief associated with public transport: state-of-the-art. Public Transp. 12(2), 455-481 (2020). https://doi.org/10.1007/ s12469-020-00231-3

Nocera, S., Cavallaro, F.: The ancillary role of $\mathrm{CO} 2$ reduction in urban transport plans. Transp. Res. Procedia 3, 760-769 (2014). https://doi.org/10.1016/j.trpro.2014.10.055

Nordtømme, M.E., Bjerkan, K.Y., Sund, A.B.: Barriers to urban freight policy implementation: the case of urban consolidation center in Oslo. Transp. Policy 44, 179-186 (2015). https://doi.org/10. 1016/j.tranpol.2015.08.005 
Oh, S., Seshadri, R., Azevedo, C.L., Kumar, N., Basak, K., Ben-Akiva, M.: Assessing the impacts of automated mobility-on-demand through agent-based simulation: a study of Singapore. Transp. Res. Part A Policy Pract. 138, 367-388 (2020). https://doi.org/10.1016/j.tra.2020.06.004

Osorio-Tejada, J.L., Llera-Sastresa, E., Scarpellini, S.: Liquefied natural gas: could it be a reliable option for road freight transport in the EU? Renew. Sustain. Energy Rev. 71, 785-795 (2017). https://doi. org/10.1016/j.rser.2016.12.104

Papanikolaou, A., Basbas, S.: Analytical models for comparing demand responsive transport with bus services in low demand interurban areas. Transp. Lett. (2020). https://doi.org/10.1080/19427867. 2020.1716474

Prins, C.: A simple and effective evolutionary algorithm for the vehicle routing problem. Comput. Oper. Res. 31(12), 1985-2002 (2004). https://doi.org/10.1016/S0305-0548(03)00158-8

Prins, C., Bouchenoua, S.: A memetic algorithm solving the VRP, the CARP and general routing problems with nodes, edges and arcs. In: Hart, W.E., Smith, J.E., Krasnogor, N. (eds.) Recent Advances in Memetic Algorithms, pp. 65-85. Springer, Berlin (2005)

Sælensminde, K.: Cost-benefit analyses of walking and cycling track networks taking into account insecurity, health effects and external costs of motorized traffic. Transp. Res. Part A Policy Pract. 38(8), 593-606 (2004). https://doi.org/10.1016/j.tra.2004.04.003

Sallez, Y., Pan, S., Montreuil, B., Berger, T., Ballot, E.: On the activeness of intelligent Physical Internet containers. Comput. Ind. 81, 96-104 (2016). https://doi.org/10.1016/j.compind.2015.12.006

Sam, E.F., Daniels, S., Brijs, K., Brijs, T., Wets, G.: Modelling public bus/minibus transport accident severity in Ghana. Accid. Anal. Prev. 119, 114-121 (2018). https://doi.org/10.1016/j.aap.2018.07. 008

Sarasola, B., Doerner, K.F.: Adaptive large neighborhood search for the vehicle routing problem with synchronization constraints at the delivery location. Networks 75(1), 64-85 (2020). https://doi. org/10.1002/net.21905

Sayyadi, R., Awasthi, A.: A simulation-based optimisation approach for identifying key determinants for sustainable transportation planning. Int. J. Syst. Sci. Operations Logist. 5(2), 161-174 (2018). https://doi.org/10.1080/23302674.2016.1244301

Schenekemberg, C.M., Scarpin, C.T., Pécora, J.E., Guimarães, T.A., Coelho, L.C.: The two-echelon inventory-routing problem with fleet management. Comput. Oper. Res. 121, 104944 (2020). https://doi.org/10.1016/j.cor.2020.104944

Secomandi, N.: A rollout policy for the vehicle routing problem with stochastic demands. Oper. Res. 49(5), 796-802 (2001). https://doi.org/10.1287/opre.49.5.796.10608

Sen, A.K., Tiwari, G., Upadhyay, V.: Estimating marginal external costs of transport in Delhi. Transp. Policy 17(1), 27-37 (2010). https://doi.org/10.1016/j.tranpol.2009.09.003

Shen, Y., Zhang, H., Zhao, J.: Integrating shared autonomous vehicle in public transportation system: a supply-side simulation of the first-mile service in Singapore. Transp. Res. Part A Policy Pract. 113, 125-136 (2018). https://doi.org/10.1016/j.tra.2018.04.004

Singh, S.K.: Future mobility in India: implications for energy demand and CO2 emission. Transp. Policy 13(5), 398-412 (2006). https://doi.org/10.1016/j.tranpol.2006.03.001

StrictArchetti, C., Jabali, O., Speranza, M.G.: Multi-period vehicle routing problem with due dates. Comput. Oper. Res. 61, 122-134 (2015). https://doi.org/10.1016/j.cor.2015.03.014

Su, B., Andelfinger, P., Kwak, J., Eckhoff, D., Cornet, H., Marinkovic, G., Cai, W., Knoll, A.: A passenger model for simulating boarding and alighting in spatially confined transportation scenarios. J. Comput. Sci. 45, 101173 (2020). https://doi.org/10.1016/j.jocs.2020.101173

Subramanian, A., Uchoa, E., Ochi, L.S.: A hybrid algorithm for a class of vehicle routing problems. Comput. Oper. Res. 40(10), 2519-2531 (2013). https://doi.org/10.1016/j.cor.2013.01.013

Tasan, A.S., Gen, M.: A genetic algorithm based approach to vehicle routing problem with simultaneous pick-up and deliveries. Comput. Ind. Eng. 62(3), 755-761 (2012). https://doi.org/10.1016/j.cie. 2011.11.025

Trentini, A., Malhene, N.: Flow management of passengers and goods coexisting in the urban environment: conceptual and operational points of view. Procedia. Soc. Behav. Sci. 39, 807-817 (2012). https://doi.org/10.1016/j.sbspro.2012.03.149

Trentini, A., Campi, A., Boscacci, F., Malhene, N.: Shared passengers and goods urban transport solutions. TERRITORIO (2011). https://doi.org/10.3280/TR2011-059006

Trentini, A., Masson, R., Lehuédé, F., Malhéné, N., Péton, O., \& Tlahig, H. (n.d.). A shared ', passengers goods', 'city logistics system. 11

Tunjongsirigul, B., \& Pongchairerks, P. (2010). A Genetic algorithm for a vehicle routing problem on a real application of Bakery delivery. 2010 2nd International Conference on Electronic Computer Technology, 214-217. https://doi.org/10.1109/ICECTECH.2010.5479956 
Ulmer, M.W., Goodson, J.C., Mattfeld, D.C., Thomas, B.W.: On modeling stochastic dynamic vehicle routing problems. EURO J. Transp. Logist. (2020). https://doi.org/10.1016/j.ejt1.2020.100008

Venkata Narasimha, K. S., \& Kumar, M. (2011). Ant colony optimization technique to solve the min-max Single Depot Vehicle Routing Problem. Proceedings of the 2011 American Control Conference, 3257-3262. https://doi.org/10.1109/ACC.2011.5991529

Viljoen, N.M., Joubert, J.W.: Supply chain micro-communities in urban areas. J. Transp. Geogr. 74, 211222 (2019). https://doi.org/10.1016/j.jtrangeo.2018.11.011

Vosooghi, R., Puchinger, J., Jankovic, M., Vouillon, A.: Shared autonomous vehicle simulation and service design. Transp. Res. Part C Emerg. Technol. 107, 15-33 (2019). https://doi.org/10.1016/j.trc.2019.08. 006

Wang, Y., Assogba, K., Fan, J., Xu, M., Liu, Y., Wang, H.: Multi-depot green vehicle routing problem with shared transportation resource: Integration of time-dependent speed and piecewise penalty cost. J. Clean. Prod. 232, 12-29 (2019). https://doi.org/10.1016/j.jclepro.2019.05.344

Wang, Y., Wang, S., Wang, J., Wei, J., Wang, C.: An empirical study of consumers' intention to use ridesharing services: Using an extended technology acceptance model. Transportation 47(1), 397-415 (2020). https://doi.org/10.1007/s11116-018-9893-4

Wh, T. (2020). Human Injury causing Road Traffic Accident at Debre Markos Town. https://doi.org/10. 21203/rs.3.rs-101705/v1

Woodburn, A.: An analysis of rail freight operational efficiency and mode share in the British port-hinterland container market. Transp. Res. Part D Transp. Environ. 51, 190-202 (2017). https://doi.org/10. 1016/j.trd.2017.01.002

Yu, B., Li, X., Xue, M.: Chapter 9-Impacts of shared mobility on energy consumption and emissions in China. In: Zhang, J. (ed.) Transport and energy research, pp. 223-242. Elsevier, Amsterdam (2020)

Zhang, X., Li, L., Zhang, J.: An optimal service model for rail freight transportation: pricing, planning, and emission reducing. J. Clean. Prod. 218, 565-574 (2019). https://doi.org/10.1016/j.jclepro.2019. 01.285

Publisher's Note Springer Nature remains neutral with regard to jurisdictional claims in published maps and institutional affiliations.

\section{Authors and Affiliations}

\section{Jihane El Ouadi ${ }^{1,2,3,4}$ D $\cdot$ Hanae Errousso ${ }^{1,2,3,4} \cdot$ Nicolas Malhene $^{3,4}$. Siham Benhadou ${ }^{1,2}$}

1 National and High School of Electricity and Mechanic, HASSAN II University, 8118 Casablanca, Morocco

2 Research Foundation for Development and Innovation in Science and Engineering, 8118 Casablanca, Morocco

3 EIGSI, 17041 La Rochelle, France

4 EIGSI, 20410 Casablanca, Morocco 